\title{
A Comprehensive Review of Protection Schemes for Distributed Generation
}

\author{
Umair Shahzad, Sohrab Asgarpoor \\ Department of Electrical and Computer Engineering, University of Nebraska-Lincoln, Lincoln, NE, USA \\ Email: umairshahzada@hotmail.com, sasga rpoor1@unl.edu
}

How to cite this paper: Shahzad, U. and Asgarpoor, S. (2017) A Comprehensive Review of Protection Schemes for Distributed Generation. Energy and Power Engineering, 9, 430-463.

https://doi.org/10.4236/epe.2017.98029

Received: July 7, 2017

Accepted: August 4, 2017

Published: August 7, 2017

Copyright $\odot 2017$ by authors and Scientific Research Publishing Inc. This work is licensed under the Creative Commons Attribution International License (CC BY 4.0).

http://creativecommons.org/licenses/by/4.0/ c) (i) Open Access

\begin{abstract}
Due to the increasing demand of energy and the need for nonconventional energy sources, distributed generation (DG) has come into play. The trend of unidirectional power flow has been gradually shifting. With new technology comes new challenges, the introduction of DG into the conventional power system brings various challenges; one of the major challenges is system protection under DG sources. These sources pose a significant challenge due to bidirectional flows from DGs as well as lower fault current contribution from inverter interfaced DGs. This paper reviews existing protection schemes that have been suggested for active distribution networks. Most of these protection strategies apply only to smaller distribution systems implying that they may need to be extended to larger systems with a much higher penetration of distributed generation. In the end, a potential protection scheme has also been recommended as a future work.
\end{abstract}

\section{Keywords}

Distributed Generation (DG), Energy, Protection Schemes, Active

Distribution Networks

\section{Introduction}

The use of fossil fuels such as coal, oil, and natural gas, for generation of electricity has many problems such as greenhouse gas emissions and global warming. Due to the increasing popularity and demand for cleaner sustainable energy, along with major blackout incidents around the world, distributed generation (DG) has emerged as a possible alternative to fossil fuels. However, the introduction of DG does pose some serious problems for the electrical power network. The power network has been inherently radial. Introduction of DG makes it bidirectional as power can flow from DG as well as the main utility grid. This pos- 
es various problems regarding system voltage profile, power quality, security, power flow control, energy management and frequency control and protection. Protection regarding DG has been a significant issue in recent years and has recently engendered much research on microgrids and DG. This is evident by the number of publications that have been and are currently being published on this topic [1]-[7].

This paper aims to comprehensively review all protection techniques which have been suggested for active distribution networks. It is expected that the work presented will be beneficial for researchers in DG protection in finding pertinent references and implementing suitable protection schemes. Consequently, application of the correct protection scheme will enhance the reliability and dependability of active distribution networks. This paper is organized in a manner that Sections 2 and 3 briefly introduces distributed generation and microgrids. Section 4 discusses some factors that can affect the performance of a protection system. Grid code requirements related to DG Protection and Low Voltage Ride Through (LVRT) are elaborated in Section 5. Sections 6.1 - 6.12 comprehensively review the protection schemes developed and proposed for active distribution networks till now. Section 7 describes the use of Phasor Measurement Unit (PMU) for protection applications. Section 8 concludes the paper along with a suggested protection scheme.

\section{Distributed Generation}

There is no concise definition of distributed generation. Various organizations and researchers define it based on their own ideas about it. However, conceptually, these definitions are quite alike. IEEE defines DG as the "generation of electricity by the facilities that are sufficiently smaller than central generating plants to allow interconnection at nearly any point in a power system". Similarly, Dondi, et al. states that "distributed generation is the generation of electrical power using a small source which is not part of the large central power system and which is in close vicinity of the load" [8]. Likewise, Ackermann, et al. defines DG as "The generation of electrical power from the source which is directly connected to the distribution network" [9]. Electric Power Research Institute (EPRI) defines distributed generation as "Smaller power sources that can be aggregated to provide power necessary to meet regular demand." From all these definitions, the definition suggested by Dondi, et al. seems most comprehensive and strict as it clearly mentions that DG source should be closer to the consumer load, whereas, the other three definitions vaguely state the location of DG connection to power system. It must be mentioned here that distributed generation should not be confused with renewable energy because the DG may include renewable technologies, non-renewable technologies, or a combination of both.

\section{Microgrids}

According to the U.S. Department of Energy (DOE), a microgrid is "a group of 
interconnected loads and distributed energy resources within clearly defined electrical boundaries that acts as a single controllable entity with respect to the grid (and can) connect and disconnect from the grid to enable it to operate in both grid-connected or island-mode".

Sources connected to microgrids are called micro sources. They include solar photovoltaic (PV) arrays, wind turbines, synchronous generators, combined heat and power (CHP) plants, micro turbines, flywheels, fuel cells, super capacitors, induction generators, electric vehicles and battery energy storage systems [10].

\subsection{Modes of Operations}

A typical microgrid operates in two modes which are defined below [11].

\subsubsection{Grid-Connected Mode}

Under this mode, the main utility grid is active. The static switch is closed. All feeders are getting their power from the main grid. In other words, critical loads (on Feeders A, B, and C) and non-critical loads (on Feeder D) are being supplied by the main grid. Figure 1 portrays this situation. PCC refers to the Point of Common Coupling [11].

\subsubsection{Advantages and Disadvantages of Grid-Connected Mode}

Grid-connected mode has some advantages and drawbacks. During a utility grid disturbance or fault, a typical microgrid can isolate from grid-connected mode to islanded mode in a seamless fashion with little disruption to consumer loads. In the times of peak load, main grid failure can be avoided by reducing the load on grid. Momentous ecological benefits are possible using low emission generators. Another benefit is the usage of both electricity and heat permitted by the proximity of generator to the consumer end. This enhances the overall energy efficiency. In this mode, ancillary services can be delivered by trading active and reactive powers of microgrid and the main grid. However, this is not the case in

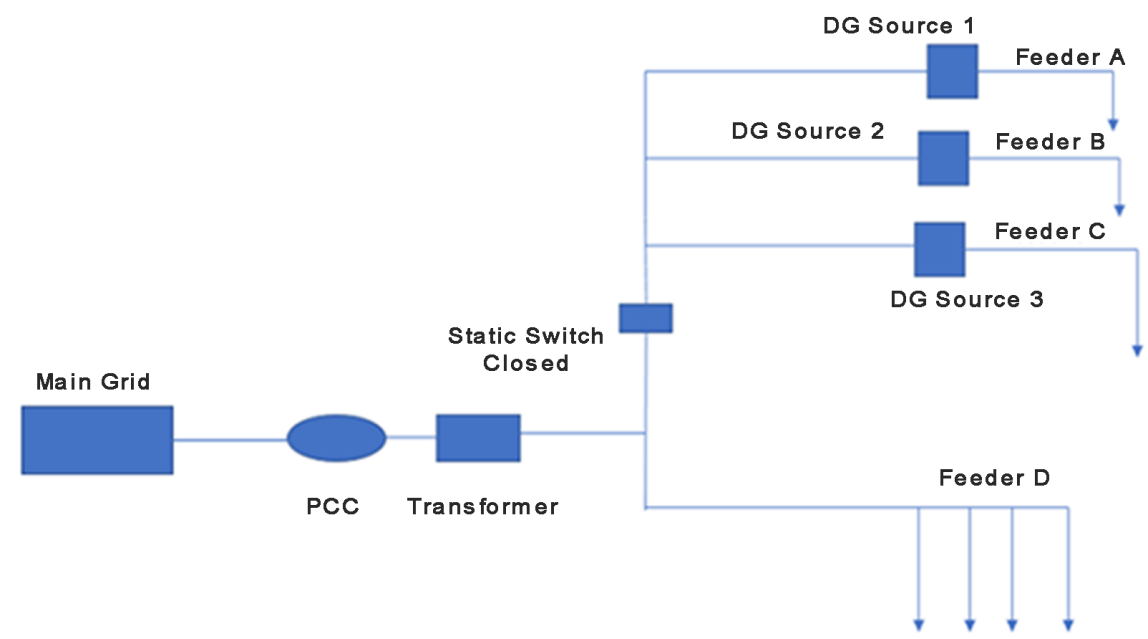

Figure 1. Microgrid: Grid-connected mode. 
the islanded mode of operation as in this mode, the real and reactive power generated within the microgrid, including that generated with the help of energy storage system, should be in equilibrium with the demand of local loads [11].

There are also some drawbacks of grid-connected mode. A major issue is that resynchronization with utility grid is a difficult action to perform. Voltage, frequency, and power quality must be controlled to acceptable standards while maintaining power and energy balance. Interconnection standards, for e.g. IEEE-1547, must be strictly followed to ensure consistency. In some situations, harmonics and DC currents are injected by the microgrid to main grid. High levels of these unwanted parameters can severely harm the operational characteristics of main utility grid. Keeping these within satisfactory levels is an immense challenge. In the grid-connected mode, power can flow from main grid to microgrid and vice versa. This can cause reverse power flows and lead to complications in protection coordination, unwanted power flow patterns false tripping, undesirable network islanding, prevention of automatic reclosing and fault current distributions. Local oscillations may develop from interaction of the control systems of DG sources, especially with inverter-interfaced DGs, requiring an exhaustive small-disturbance stability analysis. Besides, transient stability analyses are needed to guarantee seamless transition between the grid-connected and islanded modes of operation in a microgrid. Furthermore, proper methods of islanding-mode detection need to be developed [1] [12] [13].

\subsubsection{Islanded Mode}

Under this mode, the main grid is cut off and is not supplying power. The main grid might be turned off due to fault or maintenance purposes. The static switch is open. Micro-sources supply Feeders A, B and C. Feeder D is dead as it is not sensitive. In other words, critical loads are being supplied power by the micro sources and non-critical loads (on Feeder D) are cut-off from the system. Figure 2 displays this situation [11].

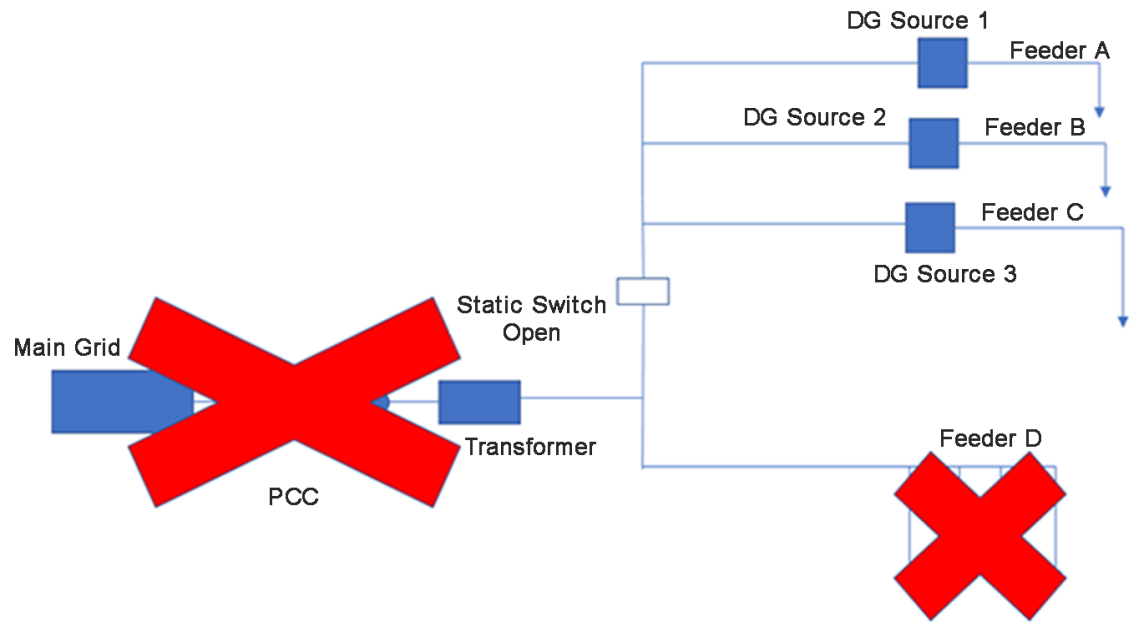

Figure 2. Microgrid: islanded mode. 


\subsubsection{Advantages and Disadvantages of Islanded Mode}

Islanded mode of a typical microgrid has some advantages and disadvantages. In this mode, a typical microgrid can act to alleviate electricity costs to its consumers by generating some or all its energy needs. It can supply power to isolated areas, where it is difficult to provide electricity using the conventional means. It can provide enhanced environmental impact and reduced carbon emissions as large number of DG sources in islanded mode are renewable sources like wind and PV panels. This mode has higher energy efficiency as compared to gridconnected mode as less energy is wasted due to proximity between power sources and load. In this mode, there are two possibilities of creating an island: intentional (scheduled) or unintentional islanding. Scheduled islanding can occur in circumstances such as scheduled maintenance, or when degraded power quality of the main grid can imperil microgrid operation. On the contrary, unintentional islanding can take place due to faults or disturbances in the microgrid. Both situations can effectively be dealt by islanded mode of microgrid. As this mode utilizes local DG sources, it also acts to make communities and businesses more resistant to future, unforeseen, circumstances, which could include natural events like large storms, earthquakes, hurricanes, or an interruption in the supply of power imported from main grid. This is because the microsources can supply power much efficiently and swiftly when it is needed rather than being sourced from a large centralized power station i.e. utility grid. This, in turn, implies that there is more price stability is islanded mode [11].

Islanded mode also has some weak points. Electrical energy needs to be stored in battery banks which require more space and maintenance. Effective means of communication within components is required in this mode of microgrid, especially, while designing protection schemes. Communication infrastructure is quite expensive to build and requires a lot of technical expertise. Unlike grid-connected mode, where large number of synchronous generators ensure a comparatively large inertia, the islanded mode might show low-inertia characteristics, especially if there is a substantial share of power electronic-interfaced DG sources. Though such an interface can augment the system dynamic performance, the low inertia in the system can cause severe frequency deviations in islanded-mode operation if a proper control mechanism is not employed. The economical and consistent operation of microgrid in this mode requires a certain level of coordination among diverse DG units. This coordination becomes more difficult as the critical demand-supply balance and naturally higher component failure rates, necessitate solving a strongly coupled problem over a protracted horizon, considering the vagueness of parameters such as profile of load voltages and weather forecast. This uncertainty is higher than that of grid-connected mode, due to the less load and highly correlated disparities of available DG sources. Islanded mode also has a regulatory issue i.e. it must coexist with the main grid. This implies that the customers in this mode of microgrid need to share some of the expenses linked to the operation and maintenance of the main grid [13] [14] [15]. 


\section{Factors Affecting Performance of Protection Systems}

There are some factors which can affect the performance of any protective relaying system. Economics is one of the most important factors. Faults are not so common; therefore, it can be thought that why there is a need to design the protection system. However, unfortunate events of faults do occur and if there is absence of protection system, large financial losses can occur. In the instance of a single fault, if the designed scheme works promptly and accurately, it can reduce the outage time and resulting equipment damage. Moreover, it is vital to reduce redundancy i.e. only use the minimum number of relays that are required for desired protection zone. The location, kind and timing of any fault occurrence cannot be predicted in the power system. Considering the undefined possibilities, the Protection Engineer must design the protection scheme considering most likely events, based upon past occurrences, suggestions made by equipment manufacturer and a decent practical judgment. As the personality of each Engineer varies, consequently, the decision to operate a protection scheme will also vary. Protection is only applicable to those points in the power system where there is availability of circuit breakers, which can isolate the faulted zone (s), or where there is presence of Current Transformer (CT) and Potential Transformer (PT), which can give the required fault information. Collaboration between system planners and protection engineers is vital for efficient and accurate working of the network. There must be some "signal" sent to protective relay in the presence of fault. This is mandatory for proper working of relay and hence, this is the most common factor affecting performance of any protection system. Some common signals are current, voltage and impedance. Any noticeable change in these "signals" implies changes in normal conditions which necessitates the relay operation. An important point to consider is that the "signal" should operate the relay only when there is significant difference between normal and abnormal conditions. For instance, the relay should not trip for inrush current of a transformer [16].

\section{Grid Code Requirements for DG-Connected Distribution Networks}

As the amount of DG connected to networks is gradually increasing, transmission network operators have started to enforce some technical requirements for their connection and operation. These requirements are known as grid codes. Since majority of DGs are connected to low and medium voltage levels, some network operators have extended the grid code requirements to distribution systems as well [17].

The major requirements for DG connected to distribution network can be broadly categorized into two types: ancillary services and Fault Ride Through (FRT) requirements. FRT is also known as LVRT. FRT capabilities are voltagetime profiles which depict the course of grid voltage as a function of time in the PCC with the DG unit. Ancillary services include support of static voltage 
(through reactive power support) and active power curbing (to attain a desired set point). FRT includes high and low voltage ride throughs and dynamic voltage support. These requirements directly affect the protection system operation. For instance, German grid code LVRT requirements for an inverter-interfaced DG are shown in Figure 3 [18] [19].

Referring to Figure 3, above limit 1, the generating plant must remain connected and deliver dynamic voltage support as in stable mode of operation. Between the limits 1 and 2, distribution network operator must decide what should be the best decision. Below limit 2, instant disconnection is accepted.

Different countries have different requirements for FRT. These requirements for DG in various national grid codes are shown in Table 1 [19].

\section{DG Protection and LVRT Requirements}

There is no doubt in saying that there a lot of technical challenges and compromises involved to maintain the LVRT requirements for DG. These challenges also include the tradeoff between potential reduction in distribution system performance versus the requirement for more complicated distribution system protection techniques to accommodate DG with LVRT abilities. When meeting the LVRT requirements, it is also essential that factors related to DG protection design such as reliability, selectivity, sensitivity, and dependability are not affected.

IEEE 1547 states that the DG unit shall cease to energize the power system for faults on the circuit to which it is connected. DGs, even synchronous generator DG, have very limited fault current contribution when compared to the fault current supplied by the grid. In the case of inverter-interfaced DGs, the fault current contribution is, in effect, zero. It is highly unlikely that a DG will be able to detect a fault on a feeder using overcurrent or distance relaying while the feeder remains energized by the substation. After the substation breaker trips, the DG is more likely to detect the fault using overcurrent or distance relaying if it has sufficient fault current contribution. This is commonly accepted to be compliant with IEEE 1547. On the contrary, in case of inverter-interfaced DGs, current is not typically an acceptable means of detecting a fault as magnitude is

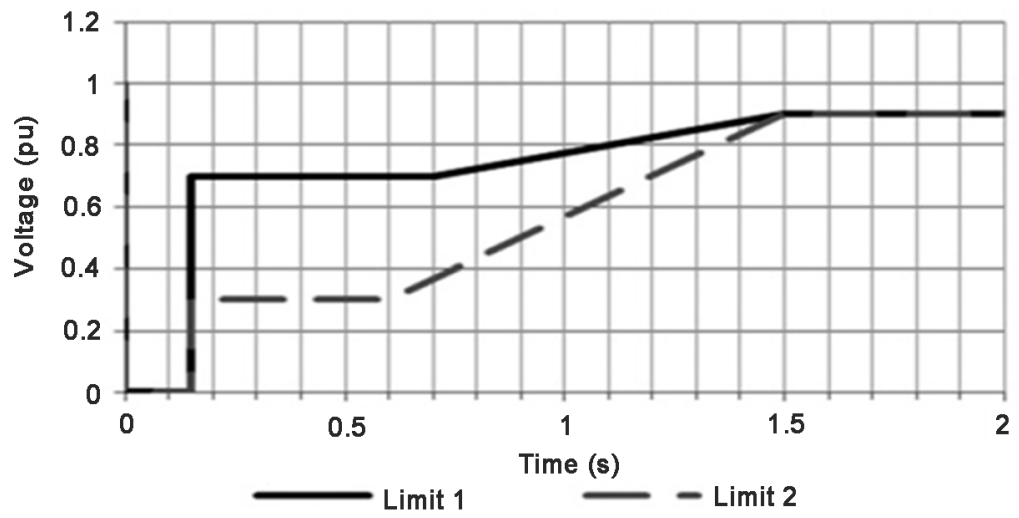

Figure 3. German grid code LVRT requirements for DG in medium voltage (MV) distribution networks. 
Table 1. FRT requirements for DG in various national grid codes.

\begin{tabular}{ccccc}
\hline Country & $\begin{array}{c}\text { Fault Duration } \\
(\mathrm{ms})\end{array}$ & $\begin{array}{c}\text { Voltage Drop } \\
\text { Level (\% of rated } \\
\text { voltage) }\end{array}$ & $\begin{array}{c}\text { Post Fault Time } \\
\text { Recovery (s) }\end{array}$ & $\begin{array}{c}\text { Reactive Current } \\
\text { Injection }\end{array}$ \\
\hline Canada & 150 & 0 & 0.18 & - \\
Denmark & 50 & 20 & 1 & Up to $100 \%$ \\
Germany & 150 & 0 & 3 & - \\
Ireland & 600 & 50 & - & Up to $100 \%$ \\
Spain & 500 & 20 & 0.5 & - \\
United Kingdom & 140 & 15 & 1.2 & \\
\hline
\end{tabular}

not high enough to trip the breaker. Such DGs typically rely on undervoltage relays for the protection. Undervoltage detection of faults is inherently quite nonselective protection tactic. To the DG, an undervoltage caused by a fault on the feeder to which it is connected is often indifferentiable from a fault on the transmission system. Enforcement of LVRT requirements intrinsically places a minimum time on the fault detection by undervoltage means. DG requirement to detect faults is mainly intended to keep DG from causing a much longer contribution of current to grid faults, thereby increasing the damage those faults can cause, as well as possible false operation of fuses or reclosers. DGs which rely on undervoltage detection of faults innately have quite less current contribution. Thus, incorporating LVRT requirements is likely if the "detect all faults" requirement is not over-interpreted to require fast tripping of DG that does not have a noteworthy contribution to fault current magnitude, and is improbable to cause fuse, recloser or relay misoperation. Suitable revision to the requirements of the new IEEE 1547 standards can be made to resolve this conflict. It is clearly understood that reclosing into an island poses a risk of an out-of-phase reclose that can possibly be destructive to synchronous generator DG connected to the island. The issue which can often be misinterpreted is that such an out-of-phase reclosing also poses a risk of transient over-voltages that may be harm the utility and customer equipment, cause large transformer and motor inrush currents that may cause undesired relay pickup or fuse operation, and torque transients potentially injurious to customer motors. The statement that out-of-phase reclose is not an issue with inverter-interfaced DG because the inverters are selfprotected, is not correct. IEEE 1547 makes the imprecise statement that the DG shall cease to energize the power system circuit to which it is connected prior to reclosure by the power system [20].

One important consequence that can affect automatic reclosing in active distribution networks is the situation when DG ride throughs a voltage disturbance due to fault on a different section. In such cases, it is mandatory for the DG to ride through a series of multiple consecutive voltage disturbances due to re-appearance of that fault upon each reclosure in the selected reclosing sequence. That series of multiple consecutive voltage disturbances experienced by 
DG can be categorized as repeating periods of abnormal voltages during the period when fault is present, separated by times of comparatively normal voltages during the times that the fault is disconnected or not in "active" state. Examples of what the DG may experience are depicted in Figure 4 and Figure 5 for two distinct cases [21].

Authors in [22] suggest that to ensure the LVRT capabilities, the present protection system for DGs must be modified. They have presented the current and future protection settings as described in Table 2 .

The settings for future protection enable an accurate LVRT implementation. If the voltage drops to $0 \mathrm{pu}$ at the PCC for a duration of less than $0.3 \mathrm{~s}$, DGs remain connected to the grid and ride-through the fault. Also, DGs must stay connected during voltage dips between $0.45 \mathrm{Un}$ and $0.8 \mathrm{Un}$ for a duration of less than $1 \mathrm{~s}$. The assumed future protection settings, shown in the bold in the Table, enable the LVRT capability of DGs and hence the first requirement to achieve a dynamic grid support. The second requirement of reactive power and voltage support, is realized with the implementation of a suitable reactive current controller.

Different Power companies have their own requirements for DG connection [23]. Some common requirements for interconnection breaker are mentioned below:

- It must be rated for service voltage and phasing.

- It must carry an ampacity rating not less than required, in accordance with the National Electric Code (NEC).

- It must be designed to open on all ungrounded conductors at the same time.

- The breaker enclosure must be suitable for its installed environment.

All power companies require that owners of DG will be responsible for providing and maintaining all equipment they think necessary for the protection of

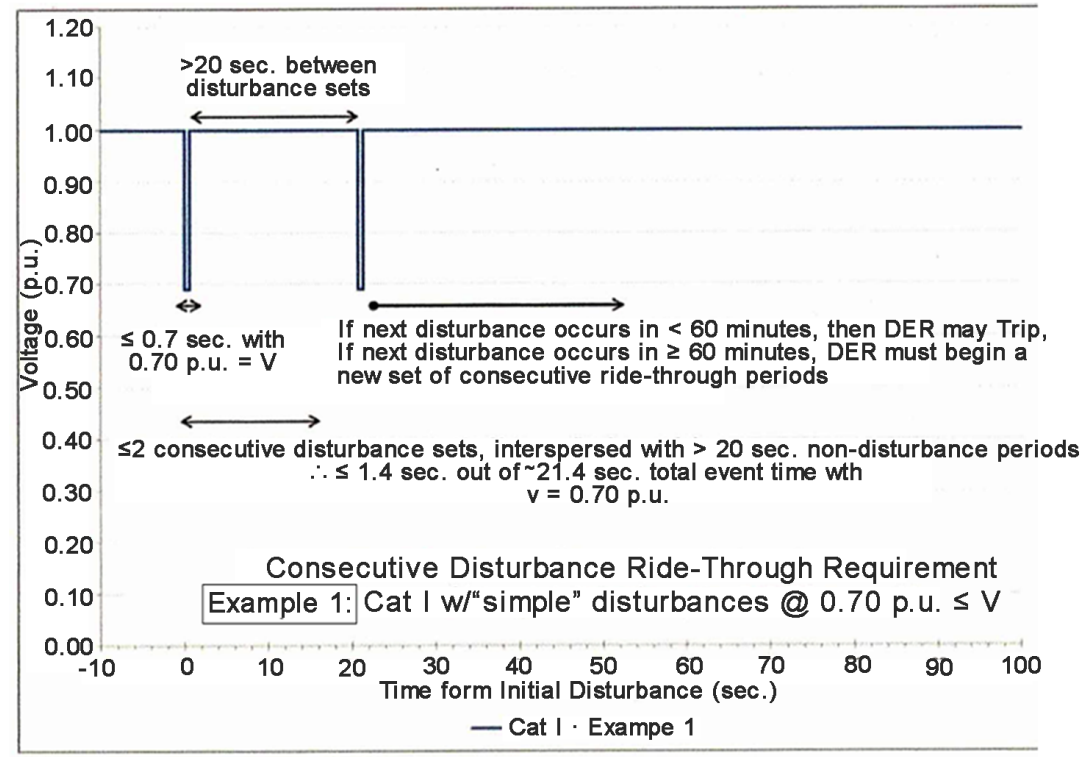

Figure 4. Consecutive disturbance ride-through requirement, Ex.1. 


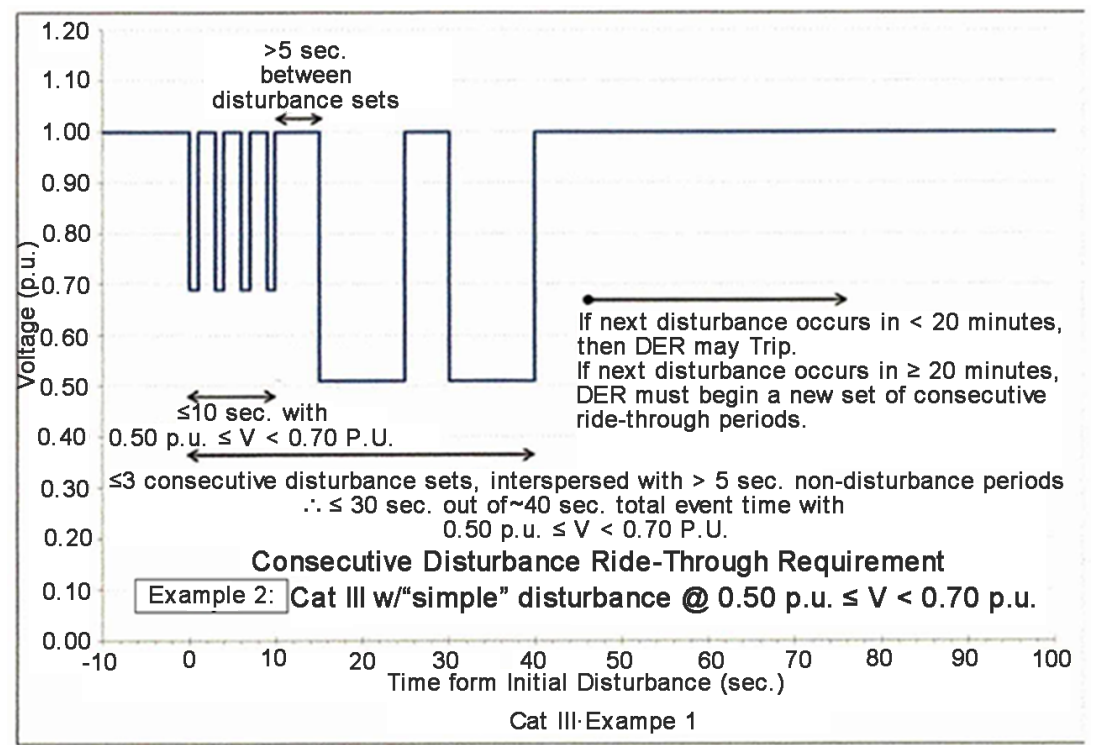

Figure 5. Consecutive disturbance ride-through requirement, Ex.2.

Table 2. Protection settings.

\begin{tabular}{ccc}
\hline Parameter & $\begin{array}{c}\text { Undervoltage Function } \\
\text { (without dynamic grid } \\
\text { support) }\end{array}$ & $\begin{array}{c}\text { Undervoltage Function } \\
\text { (with dynamic grid } \\
\text { support) }\end{array}$ \\
\hline Voltage Threshold & $0.8 \mathrm{U}_{\mathrm{n}}$ & 1) $0.45 \mathrm{U}_{\mathrm{n}}$ 2) $\mathbf{0 . 8} \mathrm{U}_{\mathrm{n}}$ \\
Tripping Time & $0.1 \mathrm{~s}$ & 1) $0.3 \mathrm{~s} 2) 1 \mathrm{~s}$ \\
\hline
\end{tabular}

their operations [24]. Moreover, all protection, safety, and interconnection equipment installed by owners of DG must meet standards of good engineering and electrical safety practices, comply with North American Electric Reliability Corporation (NERC) and be capable of parallel operation with the electrical power system. A basic requirement, related to protection equipment, is to provide satisfactory protection facilities by the owner to protect the company service wires from fault currents and under/over voltage conditions originating from the DG facility or electrical system.

Most companies require the customer to connect these relays when interconnecting a DG source greater than $5 \mathrm{MW}$ : undervoltage, directional power, overvoltage, directional overcurrent, and frequency [25]. As an example, DG connection requirements of Nebraska Public Power District (NPPD) are summarized in Table 3 below. The numbers are American National Standards Institute (ANSI) device designations for protective relays and they have been described below the table.

\section{Protection for DG-Connected Distribution Networks}

Sections $6.1-6.12$ comprehensively review the protection schemes developed and proposed for active distribution networks till now. All schemes presented are based on MV levels, however, schemes presented in Sections 6.1, 6.4, 6.5, 6.7, 
Table 3. NPPD DG connection requirements.

\begin{tabular}{ccc}
\hline Size of DG & Operating Characteristics & Required Protective Relays \\
\hline Up to $25 \mathrm{~kW}$ & Sustained Parallel Operation & $25,27,59,81 \mathrm{O}, 81 \mathrm{U}$ \\
$25 \mathrm{~kW}-1 \mathrm{MW}$ & Sustained Parallel Operation & $25,27,59,81 \mathrm{O}, 81 \mathrm{U}$ \\
$1 \mathrm{MW}-5 \mathrm{MW}$ & Sustained Parallel Operation & $25,27,59,81 \mathrm{O}, 81 \mathrm{U}, 67,67 \mathrm{~N}$ \\
Greater than $5 \mathrm{MW}$ & Sustained Parallel Operation & $25,27,59,81 \mathrm{O}, 81 \mathrm{U}, 67,67 \mathrm{~N}, 32$ \\
\hline
\end{tabular}

25: Synchronism Check Device; 27: Undervoltage Relay; 59: Overvoltage Relay; 81O: Over-frequency Relay; 81U: Under-frequency Relay; 67: Directional Overcurrent Relay; 67N: Directional Overcurrent Relay (with a Neutral); 32: Directional Power Relay.

6.10 and 6.11 can be termed as "modern" protection techniques and those in Sections 6.2, 6.3, 6.6, 6.8 and 6.9 can be termed as "conventional" techniques.

\subsection{Protection Using Communication}

Reference [26] devised a differential protection scheme employing digital relays and a communication system. According to the scheme designed, the primary protection in grid-connected mode is based on a differential scheme where each feeder segment trips the switching device on both ends of a faulted feeder. Under islanded mode, the scheme detects high impedance faults. The main drawback of the scheme is that it does not consider errors and mismatches which take place in current transformers. Moreover, placement of switching devices and relays at both ends of feeders is quite costly.

In [27], simulations are carried out for a radial grid-connected distribution system using an integrated control and protection unit. The authors have designed an instantaneous overcurrent pilot protection scheme using an Ethernet communication technique. The integrated unit measures current, voltages, and other associated parameters to make protection decisions which are communicated to relays and circuit breakers. The major flaw of the technique is that it does not consider communication failures and non-availability of communication channels to transfer the required signals. Potential solutions suggested in [28] [29] [30] employ a central computer to regulate the settings of protective devices upon receiving data about network topologies and distributed generation connections or disconnections. This action is performed to maintain coordination between various devices, although, coordination may cease to exist during the time between the network reconfiguration process and the computation of updated settings. The downside of the scheme is that it assumes that all existing protective devices have been updated to their digital counterparts. Moreover, a wider use of communication implies that the system will be more vulnerable to cyber attacks.

Reference [31] employs a directional comparison blocking (DCB) protection scheme using radio communication. The directional elements present in the substation are adjusted in such a way that they respond only to upstream faults and consequently transmit a blocking signal to the DG source. This signal is 
connected to the local protection through an AND gate connected inverter (NOT gate). This combination of AND-NOT gates plays a vital role in preventing tripping of substation circuit breakers. Local protection lags due to latency of the radio channel. Moreover, the time delay must be adjusted in such a way that it is greater than the lengthiest projected channel delay. Therefore, radio links possessing low average channel latency but high maximum channel latency should not be used in DCB schemes. Numbers 67 and 50 indicate directional overcurrent relay and instantaneous overcurrent relay, respectively. Figure 6 shows the implementation of this scheme.

In [32], the authors used Simscape Power Systems ${ }^{\mathrm{Tw}}$ (formerly Sim Power Systems ${ }^{\mathrm{rm}}$ ) toolbox of MATLAB to model a small segment of distribution network as if it were a microgrid. They used a variety of renewable DG sources and one dispatchable source. They simulated the four main fault types including the three-phase fault at each bus in both the grid-connected and islanded modes. Consequently, analysis of fault currents and voltage levels was done to find out how the protection scheme of the distribution network would need to be altered to ease microgrid functionality. The results show that the standard protection methods are insufficient and hence, the authors suggest the use of digital relays connected to breakers. These digital relays are programmable and work on the concept of communication amongst various components of the active distribution network.

In [33], an algorithm for protection of distribution networks in presence of DG is suggested. The algorithm uses network zoning approach. In this approach, each zone is an independent section, possessing the ability of islanding operation whenever required. In the algorithm, after dividing distribution system into numerous independent zones, a computer-based relay identifies the exact fault location by making comparison between required measured currents and results of offline computations. It then sends required signals to protection devices to isolate the faulty zone from the healthy network. Besides, the algorithm can accurately perform reclosing operation and coordination with fuses of network. All four faults, including the three-phase faults, have been considered and simulations are performed using DigSILENT Power Factory and MATLAB. The

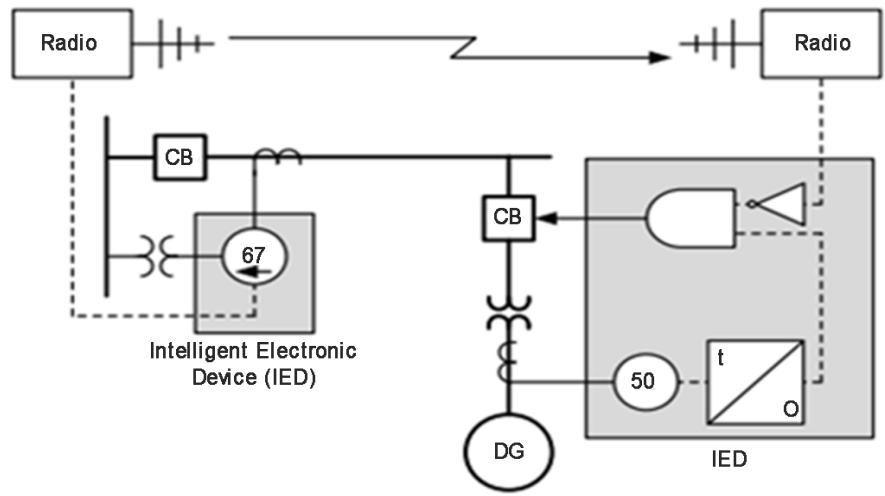

Figure 6. Directional comparison blocking scheme using radio link communication. 
proposed idea has some drawbacks, for instance, the algorithms cannot identify high impedance faults. The number of zones increases with increase in the number of DGs. This results in requirement of having many isolating circuit breakers, which will incur more cost and hence, the scheme may not prove to be economic.

In general, protection techniques involving communication are a good alternative to conventional schemes but their high cost makes them unsuitable for application in distribution networks. A generic schematic for protection employing communication is shown in Figure 7. Sensors S1 and S2 communicate the significant data (voltages, currents etc.) with the communication and control center. Protective relays are represented by R1 and R2.

\subsection{Voltage Based Protection}

References [34] [35] describe a voltage-based scheme for the protection of microgrids in islanded mode. The utility voltages are measured and transformed suitably to identify the kind of fault depending on the voltages measured. In [34], the authors show that if the disturbance voltage increases the threshold voltage corresponding to a fault, the faulted zone is tripped. In [35], they utilized communication to transfer voltage signals between any two relays to gauge the zone of fault. The process consists of two steps. In the first step, supply voltages are converted from abc frame to dq frame. In the second step, the disturbance signal, denoted by $V_{D I S T}$ is determined by using disturbed dq values. This signal characterizes the deviation of supply voltages from a set reference. The greater the value of this signal, the greater the disturbance. The disturbance signal is an indicator that disturbance is present in the system. It is passed and processed through a low pass filter (LPF) and a hysteresis comparator (HYS). Lower and upper limits of a comparator determine fault detection sensitivity. The scheme has a great advantage in that it protects internal and external faults regarding any protective zone. However, it totally ignores high impedance faults and symmetrical faults. A block diagram of the scheme is shown in Figure 8 [36].

A voltage-based protection scheme based on a Park transformation of system voltages is described in [37]. The most significant feature of this scheme is that it could be used for various configurations of microgrids.

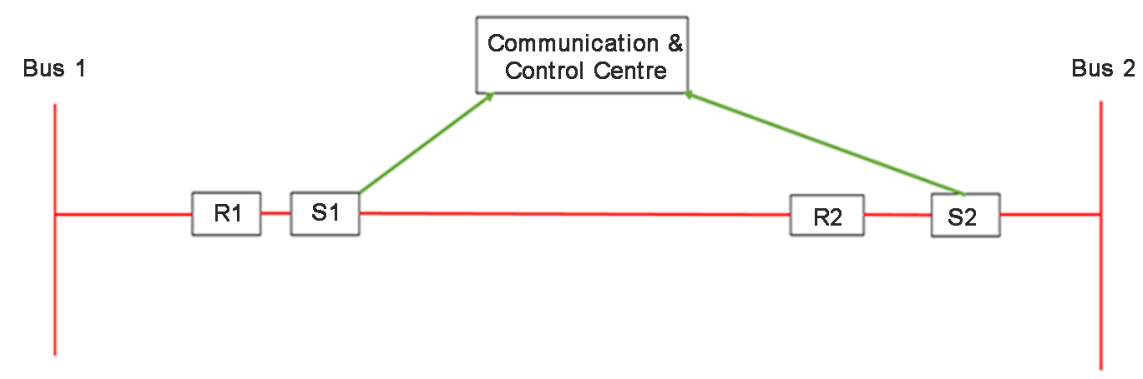

Figure 7. Schematic for protection using communication. 


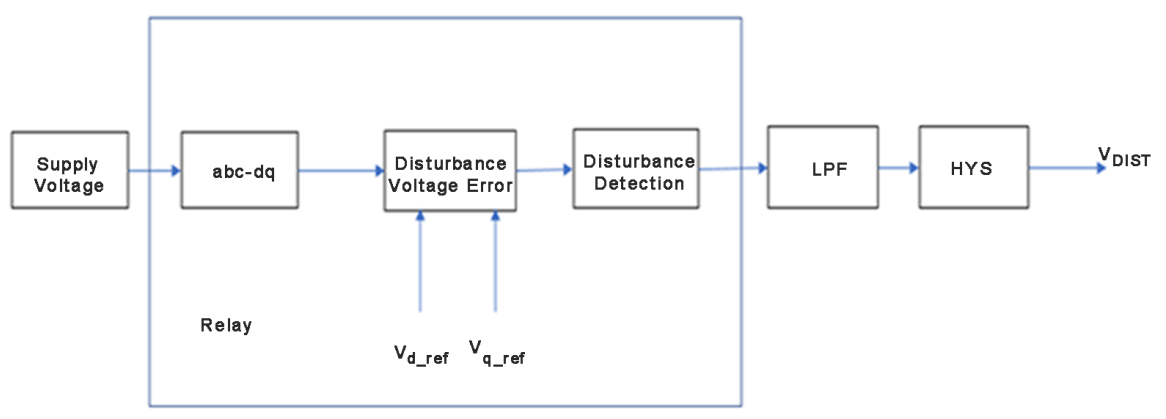

Figure 8. Voltage based protection.

Most voltage-based protection techniques apply to specific configurations of microgrids. Thus, they cannot be applied universally to every microgrid. High impedance faults cannot be picked up using this protection. Park transformation calculations are much more complex in determining when the network topology becomes large [38].

\subsection{Impedance (and Admittance)-Based Protection}

This method is based on calculating impedance (or admittance) at the fault location by measuring associated voltages and currents. Impedance-based fault location methods are classified into two main categories; the first category relies on measurement of voltages and currents at the main substation only [39] [40] [41] and the second method considers measurements at both the substation and DG location [42] [43] [44].

Bolted three phase faults were considered in [42] [43] employing the first and second categories. The major flaw in this work was not considering any fault impedance and the method being applicable to networks having low DG penetration. $10 \Omega$ fault resistance was considered in [44] along with varying capacities of DG. Techniques described in [42] [43] [44] utilize measurements at both substations and DG locations. They require an appropriate communication method to effectively transfer the signals from DG locations to main substation.

Authors in [45] utilized EMTP (Electro Magnetic Transient Program) software to carry out impedance-based fault analysis on a $11 \mathrm{kV}, 27$ nodes distribution network. They simulated single-line-to-ground fault and three phase faults with a fault impedance of 50. A major advantage of their methodology is that their technique only uses local measurements at main substation and depends on sequence components.

Authors in [46] have proposed detection of fault using the reciprocal of impedance i.e. admittance. The generic block diagram of their technique is shown in Figure 9.

Here, Ym represents the admittance between relay " $R$ " and an arbitrary point $\mathrm{K}$ and $\mathrm{Yt}$ is the total admittance. The ratio of $\mathrm{Ym}$ and $\mathrm{Yt}$ is denoted by $\mathrm{Yn}$ which is the normalized admittance. According to the design, the value of $Y n$ is greater than 1 indicates the presence of fault. The main flaw of this scheme is that it is only applicable to networks with lower DG penetration. 


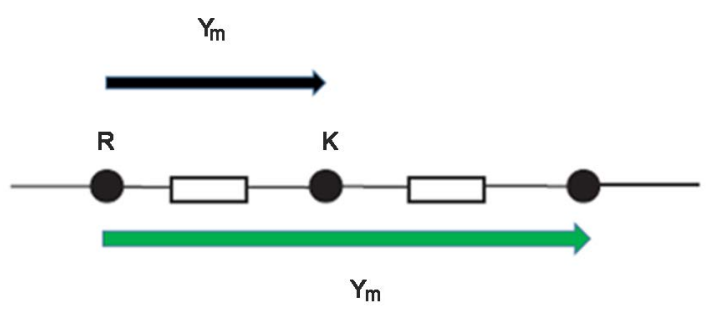

Figure 9. Schematic for protection using admittance.

Reference [47] proposes a protection method based on positive sequence impedance which is applicable to a $10-\mathrm{kV}$ distribution network with inverter-interfaced DG units. The suggested method is resistant to the vagueness of output capacities of inverter-interfaced DGs and the diversity of power flow in numerous fault cases. An operation criterion with limiting characteristic can enhance the sensitivity of protection. The scheme does not require synchronous fault data measurement and demonstrates a stronger ability to resist transition resistance. The simulations are performed using PSCAD/EMTDC and the scheme considers both symmetrical and unsymmetrical faults.

\subsection{Current-Based Protection}

A protection strategy based on the principle of current travelling waves is introduced in [48]. The fault is sensed by measurement of local voltages at system bus bars and fault location is determined using current travelling waves. There is a variation in magnitude of power frequency voltage at the faulted bus. Measurements from current transformers are employed for travelling waves and wavelet analysis is used for disintegration of travelling waves. By comparison of magnitude and polarity of initial travelling waves, the feeder which has fault is determined. Both symmetrical (three-phase) and unsymmetrical (single line to ground, line-line, double line to ground) faults are considered in the simulation process. Block diagram implementation of this scheme is shown in Figure 10.

\subsection{Adaptive Protection}

In adaptive protection techniques, the calculated relay settings are stored in a database according to network topology. When there is a change in topology, the relays update their values from the database system [49].

An adaptive protective scheme for a low voltage microgrid where a communication network connects a microgrid management system and various components of the microgrids is proposed in [49]. The microgrid management system detects any change in Microgrid configuration and sends appropriate settings to protective devices. Although the scheme enjoys the advantage of protection in both grid-connected and islanded modes, the possibility of communication failures has been neglected. Moreover, it does not encourage the plug and play of DG sources. This means that there are restricted locations where DGs can be placed in the network. 


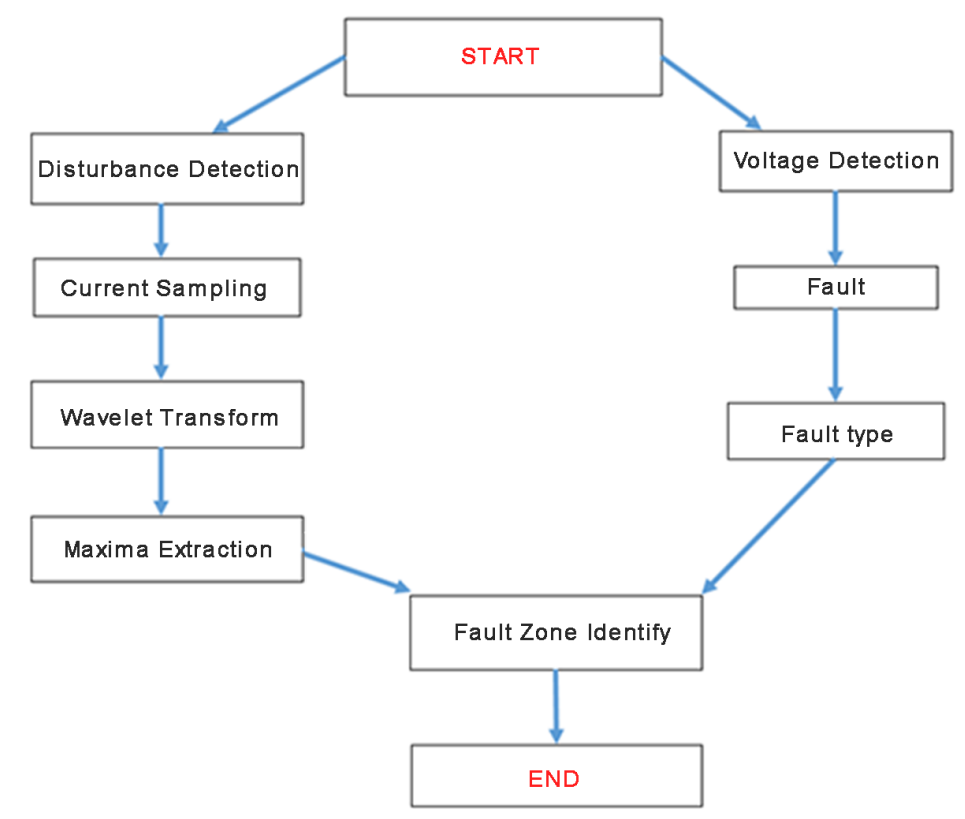

Figure 10. Schematic for protection using admittance.

A protection scheme based on a microgrid central protection unit using an Ethernet communication network is suggested in [50]. In this scheme, the micro grid central protection unit (MGCPU) receives interrupts to calculate and update the operating fault currents in the relays. When the measured currents are greater than the relay operating currents, the relays near the fault send signals to the MGCPU to set their fault detection statuses. The relays that detected the fault trip the circuit breakers to isolate the fault. The major drawback of this scheme is that it is not applicable to complex systems involving continually varying relay connections. The dynamic behavior of the communication network has also been ignored.

In [51], an adaptive protection scheme is suggested for an active distribution network to overcome the challenges posed by overcurrent protection. Three gas turbine generators and one CHP plant are used as DG sources. DigSILENT Power Factory software is used to carry out the simulations. The authors considered a three-phase fault with a resistance of $0.05 \Omega$ for the simulations. The scheme utilizes local information and state detection algorithms to update the relay trip characteristics by sensing operating modes and faulty section of the system. The simulation results accurately identify the mode of operation and faulty segment and demonstrate how the settings of the designed adaptive protection scheme can be updated for faster fault clearing. Authors in [52] modelled an electronically coupled DG with an adaptive protection scheme. The electronically coupled DG is a microgrid framework formed by electronically coupling the renewable energy sources. PV and wind are used as DG sources. Further, the proposed scheme provides a suitable protection to the microgrid for a threephase fault, regardless of the operation mode of the microgrid. An impressive 
feature of the developed scheme is that it monitors the microgrid and instantly updates relay fault current, according to the variations that take place in the system. Moreover, it employs auto-reclosures, through which the system recovers faster from the fault, thus, enhancing the reliability of the microgrid. The efficacy of the scheme is investigated using the time-domain simulations performed on PSCAD software.

A conceptual block diagram for a DG connected distribution employing adaptive protection is shown in Figure 11.

The major flaws identified in this protection are that the system needs quite large memory to store protective settings for larger system topologies. Upgrading of protective devices (fuse, recloser etc.) currently present in the system is required. All possible topologies of the microgrid need to be completely known before applying this scheme. Establishing a communication infrastructure requires a lot of investment [38] [53].

\subsection{Differential Protection}

Reference [54] proposes a distinct differential protection scheme for protection of microgrids in islanded operation. Instead of the conventional differential line protection scheme, the scheme uses the concept of differential zone protection. The authors developed an algorithm for appropriate placement of sensors and relays. Although, the scheme has the advantage of fewer relays and cheaper sensors, but it has not been tested experimentally.

In [55], a protection scheme based on differential current is described. It employs overcurrent relays and communication links in a microgrid having converter-based and directly coupled DG sources. This scheme is economically beneficial but is ineffective under unbalanced load conditions. The design is applicable to three phase faults and uses DigSILENT Power Factory for the simulations.

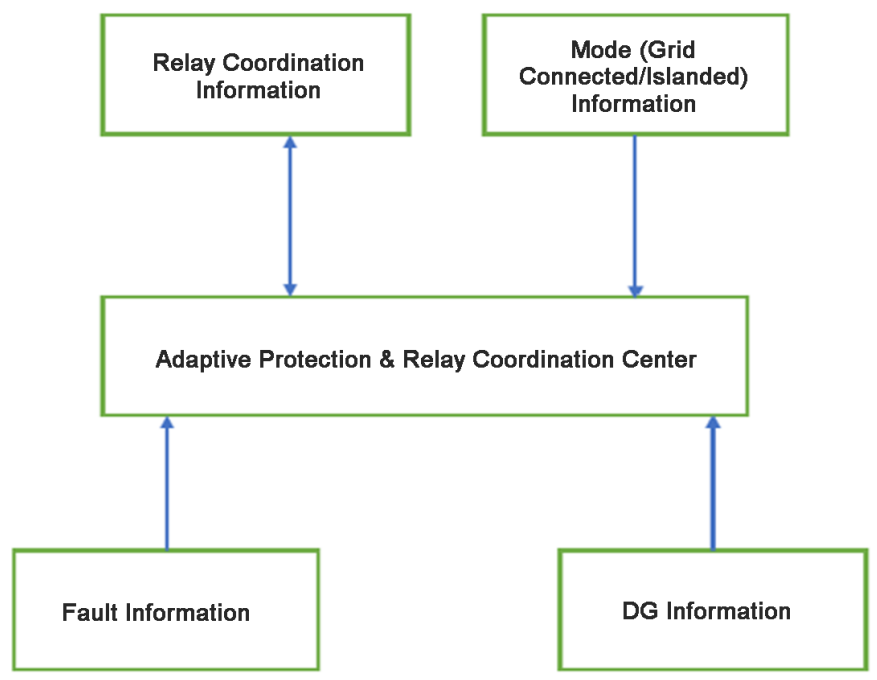

Figure 11. Adaptive protection. 
Reference [56] proposed a protection scheme for a MV active distribution network. The scheme is primarily dependent on differential protection. In the event of primary protection failure, a robust backup protection scheme is developed to isolate the fault after a specific time. The suggested primary protection scheme is applicable to the whole system, regardless of the operation mode. This scheme is simulated on an 18-bus distribution system containing a high penetration of distributed energy resources i.e. wind, PV, and diesel generator. The results are obtained using MATLAB simulations. All types of faults, including the three-phase-to-ground fault, are considered.

In general, a differential scheme suffers from three major problems. As there is a valid possibility of communication system failure, inclusion of aback up protection scheme in the design is mandatory. Establishing communication network and related links is relatively expensive. Unbalanced loads may cause some problems for this kind of protection. Problems can arise due to transients when connecting and disconnecting distributed generation sources [38]. A general block diagram for differential protection employing communication in DG-connected systems is shown in Figure 12. The current transformer and circuit breaker are denoted by $\mathrm{CT}$ and $\mathrm{CB}$, respectively.

\subsection{Pattern Recognition Protection}

A differential energy based protection scheme employing time-frequency transform technique, also known as Stockwell Transform (S-transform), has been suggested in [57] [58] for medium voltage microgrid with loop network and converter based distributed generation sources. In the suggested protection scheme, firstly the currents (F1, F2) at both ends of faulted line are found from the respective buses which are then passed through an improved S-transform and their equivalent time-frequency contours are produced. The spectral energy content of these contours of fault current signals is found out and consequently, the differential energy is calculated. Fault patterns can easily be recognized using the differential energy of these time-frequency contours. The trip signal is issued based on a pre-set threshold on the differential energy for various fault scenarios in microgrid. The simulation results indicate that the differential energy changes

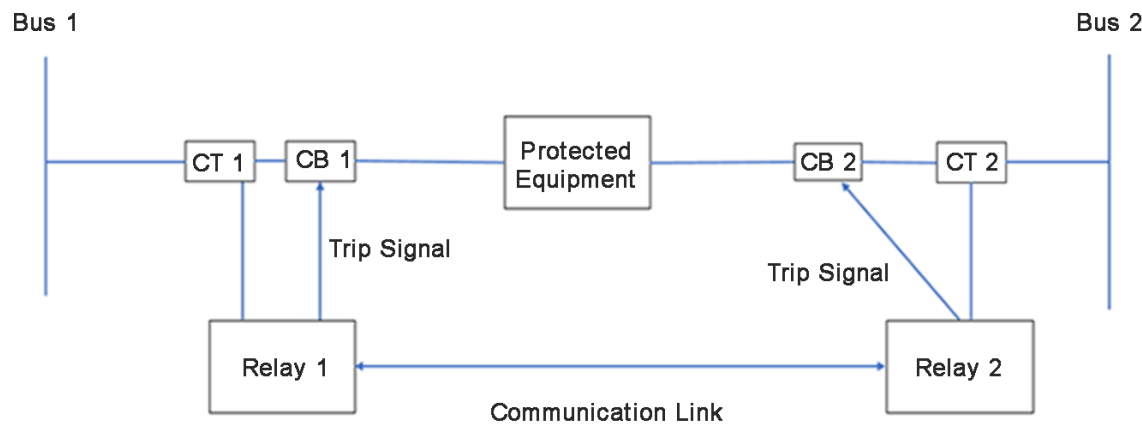

Figure 12. Differential protection. 
noticeably in the faulted phase as compared to healthy phase and thus, faulted phase can simply be recognized. An advantage of this scheme is that it is applicable to all kinds of faults including three phase bolted faults and high impedance faults. A drawback of this scheme is that it requires both time and frequency data to operate accurately [59]. A block diagram depicting the process of Pattern Recognition Protection is shown in Figure 13.

\subsection{Overcurrent Protection}

Overcurrent (OC) protection is one of the most effective and efficient methods when applied to traditional radial distribution networks. Combined with a directional element, they form a strong entity to protect the distributed grid in gridconnected mode [60].

The IEEE 13 bus system with wind turbines as DG sources (in islanded mode) is used in [61] to observe a three-phase fault at a location defined by the user. The authors changed the locations of DGs to observe the variations in fault current levels. They utilized directional overcurrent relays to counter the bidirectional flow of the current. The major discrepancy in this work lies is not considering other types of DG. Penetration levels of DG are also kept constant. The effect of grounding is ignored and only a three-phase fault is considered.

Reference [62] uses MATLAB ${ }^{\circledast} /$ Simulink $^{\circledR}$ to demonstrate overcurrent protection for a system containing three wind turbines. Three phase faults are considered at each circuit breaker in the network. The results indicate that overcurrent relays can be effectively used for protecting wind power plants for worst case fault scenarios (solid three phase faults). International Electrotechnical Commission (IEC) settings are used for coordination of over current relays. There are three major types of over current relays: definite current (or instantaneous), definite time and inverse time. The most common type is the latter one. It has the characteristic such that the higher the fault current, the lower the tripping time. Different characteristics of over current relays based on the IEC standard are shown in Table 4 [62]. Here, " $P$ " represents the inverse of the pickup current value. The time setting multiplier is designated by TSM.

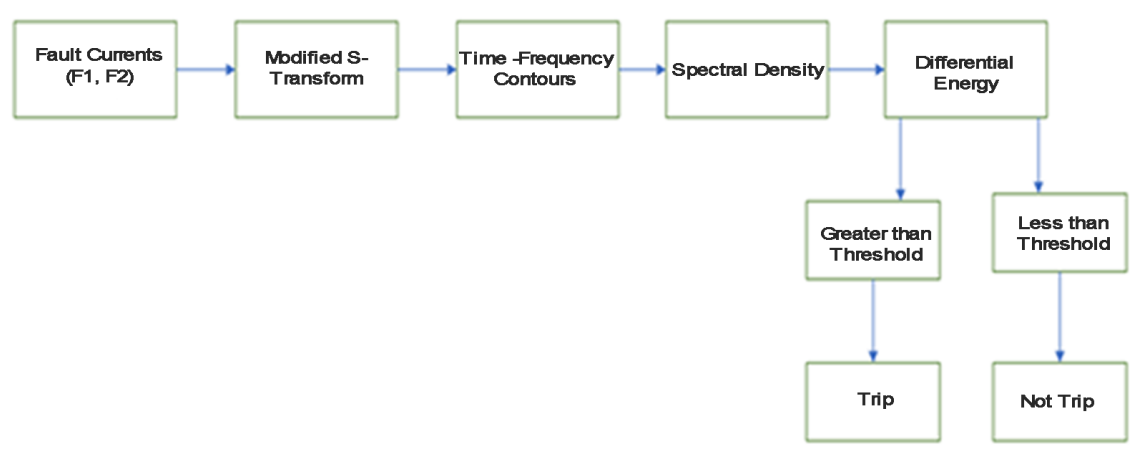

Figure 13. Pattern recognition protection scheme. 
Table 4. Different characteristics of overcurrent relays based on IEC standard.

\begin{tabular}{cc} 
Type of OCR & Operation Time (s) \\
Normally Inverse & $\frac{0.14 * T S M}{I^{0.02}-1}$ \\
Very Inverse & $\frac{13.5 * T S M}{I^{1}-1}$ \\
Extremely Inverse & $\frac{80 * T S M}{I^{2}-1}$ \\
Long Time Inverse & $\frac{120 * T S M}{I^{1}-1}$ \\
\hline
\end{tabular}

The authors in [62] have coordinated the relays per Figure 14. Overcurrent Relay No. 1 (OCR1) acts as the main relay, while the other two relays are back up relays, in case the main relay fails to operate.

In [63], a protection scheme combining directional overcurrent and differential components is described. Synchronous generators are used as sources of DG. The flaw in this scheme is that it considers only three-phase faults. Moreover, no other sources of DG are considered. The scheme has not been implemented on various topologies.

Reference [64] utilizes DigSILENT Power Factory software to implement overcurrent relays for protection of a three-phase fault (with a finite fault impedance) at a line in distribution system integrated with DG. The authors compared the magnitude of fault currents for both the grid-connected and islanded modes. They used two wind turbines and five gas turbine generators as sources of DG. A positive attribute of the scheme is that the authors managed to incorporate directional relays for protecting upstream faults, however, the flaw is that the same has not been done for unsymmetrical faults.

Reference [65] shows how overcurrent relays with no directional elements can cause coordination problems. This is depicted in Figure 15. Circuit breakers are denoted by " $\mathrm{CB}$ " and distributed (or embedded) generation sources are denoted by "EG". As seen, circuit breakers CB1 and CB3 will receive a fault current opposite to normal flow. The "star" indicates the fault point. This can cause coordination problems. However, if the fault is downstream, as shown in Figure 16, all breakers will see a fault in "same" direction. The authors also concluded that location of fault and DG can also play an important role in coordination and selectivity of over current relays.

A distribution network using NEPLAN ${ }^{\circledR}$ software with wind turbines as sources of DG has been simulated in [66]. The authors modeled wind turbines using induction generators. They changed the number of DGs in the system and observed the tripping of over current relays. Their work gave three important results. Firstly, penetration of DG in a distribution system causes an increase in fault current at any fault location. Secondly, it causes the distribution system to drop its inherent radial power flow features. Lastly, as the distance between the DG and the fault location increases, the magnitude of the fault current declines.

Reference [67] suggests a practical setting profile for overcurrent protective elements in an active distribution system with synchronous generator as the DG 


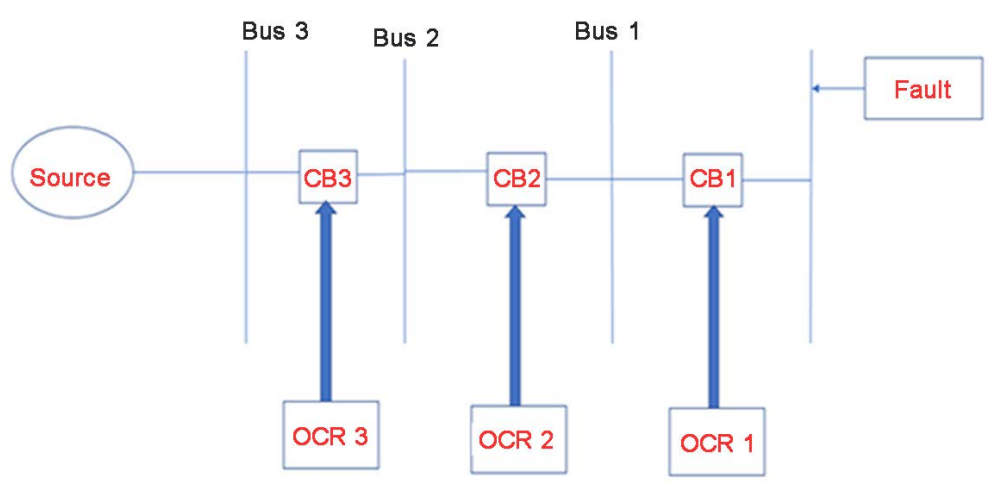

Figure 14. Coordination of overcurrent relays (OCR 1, OCR 2, OCR 3).

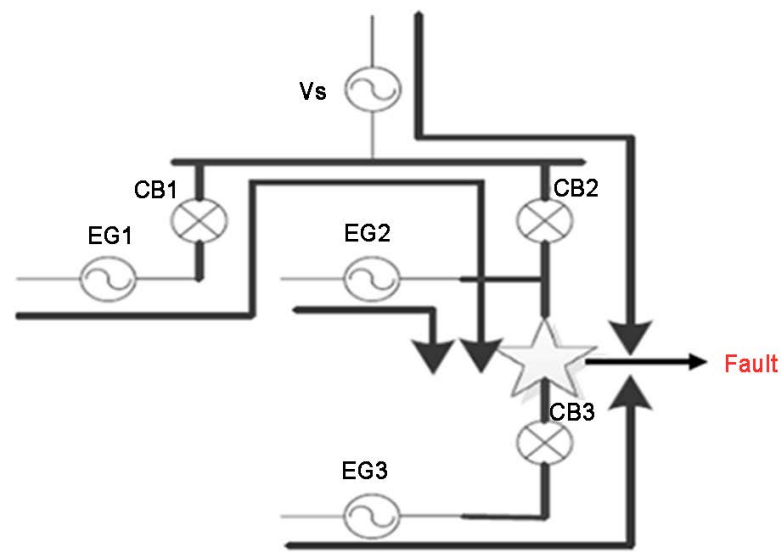

Figure 15. Overcurrent protection coordination problem.

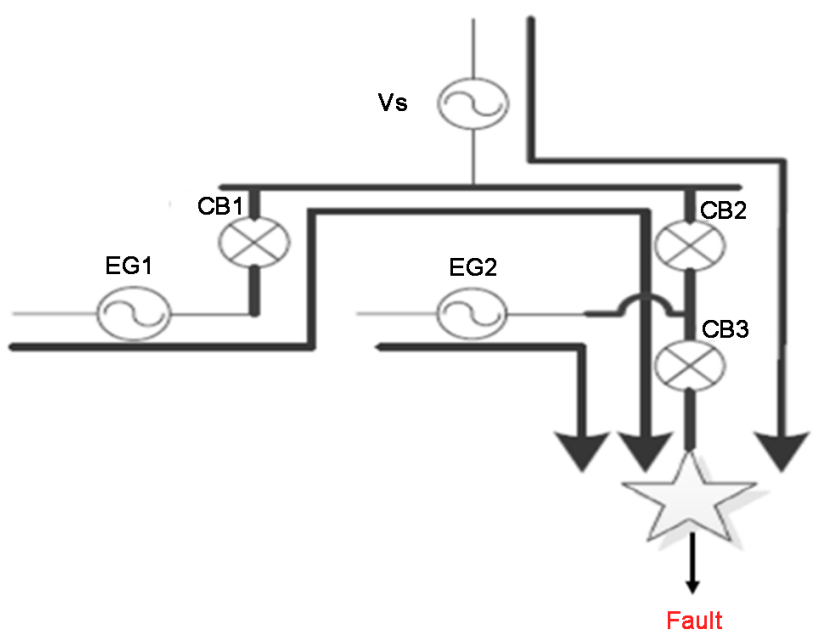

Figure 16. Overcurrent protection coordination.

source. A typical $11 \mathrm{kV}$ underground distribution feeder is modeled while considerable amount of DG penetration is fed in. Several locations and sizes are considered for the DG. For simulation purposes, MATLAB is employed. Threephase faults are considered on three different feeders and at the location of load 
fuses. The results verify an improved comprehension of the essence of DG problems in active distribution systems and contribute in realizing an enhanced state-of-the-art protection coordination, faster fault clearing times and augmented selectivity for overcurrent relays in the presence of DG sources.

\subsection{Distance Protection}

This protection offers high selectivity, particularly when applied to transmission lines. Impedance at each relay location is calculated by dividing the voltage at the relay location by the current flowing through it. Usually, three zones are defined for the region to be protected. The settings of zones are normally done in such a way that the relay over reaches the required protection setting (in three zones) to ensure that the line will be protected [68].

Reference [69] uses distance relaying with Mho characteristics in a microgrid protection plan. Per the devised protection criteria, Zone 1 covers $80 \%$ of the protected line; and Zone 2 covers the entire line plus $50 \%$ of the subsequent line. However, the work proved that this distance relaying may lead to a needless operation scenario due to violation of coordination rules.

In [70], distance protection on a MV microgrid in Aalborg, Denmark, using DigSILENT Power Factory software is demonstrated. Different modes of the network are analyzed and tested. Wind turbines are used as sources of DG. The simulation results show that variations of fault currents seen by forward relays are much larger than backward relays. Three phase faults, with varying fault resistance, are considered for four different scenarios. For each scenario, rated capacity of wind turbine is varied.

A distance protection scheme is suggested in [71]. The advantage of this scheme is that it is directional and hence, it is suitable for non-radial networks. However, a drawback of the designed scheme is the connection of a potential transformer which represents a critical extra expense as compared with traditional overcurrent protection. However, it can be contended that the potential transformer is redundant as the voltage sensor can be connected to the low voltage side of the distribution transformer. The non-radial nature of a distribution network would enhance the reliability and dependability of that distribution network if protection selectivity and discrimination can be attained successfully.

Distance protection enjoys the main advantage in that it does not need communication between each relay. Its main objective is to calculate the impedance at the fundamental frequency between relay location and fault point. Moreover, it can accurately protect the system from the worst-case fault scenario (threephase bolted) as far as the fault is within the required protection zone. However, a major problem in distance is inaccuracy in measuring fault impedance i.e. impedance from the relay till the point of fault. Increased tripping time due to downstream source infeed can also be a potential issue. The application of distance relays is limited to transmission lines but, in some cases, can also be applied to distribution lines [38]. A general schematic for a distance relaying zone is shown in Figure 17 [72]. 


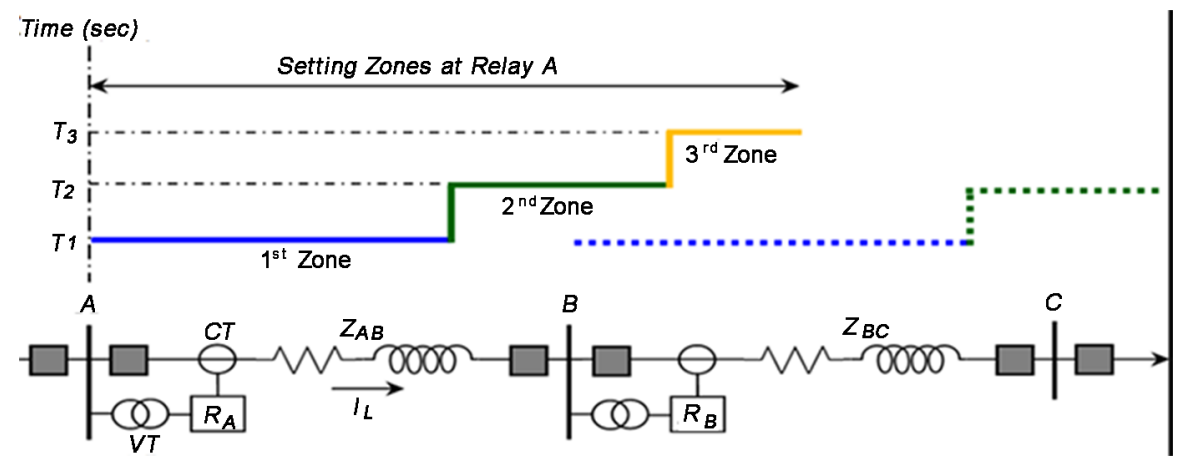

Figure 17. Distance protection scheme.

\subsection{Multiagent Protection}

A typical multiagent is a combination of hardware and software agents distributed in the network which collectively work to achieve a desired global goal. In this case, it is the protection of the power system. The architecture needed for an adaptive multiagent over current scheme consists of three main layers as shown in Figure 18 [68].

These three layers are called the equipment layer, substation layer and system layer. The overcurrent relays are in the equipment layer. It is the lowest layer which also contains the measurement (management), protector, performer, and mobile agent. The substation layer communicates with the equipment layers and sends the information to the system layer. The substation layer includes region, mobile, and management agents. The system layer is the highest layer which monitors the entire network by communication with substation layer [68] [73] [74] [75].

In [76], a fault diagnosis method for an active distribution system using the concept of multiagent systems has been suggested. Java Agent Development Framework (JADE) has been utilized to implement the proposed multiagent system. The proposed method is verified using a modified 32 node active distribution system. The main drawback is that only a single kind of DG is tested on this scheme.

In [77], a fault diagnosis method based on multiagent system is suggested. The proposed method is designed for the purpose fault location and isolation in a 16-bus power distribution system in the presence of DG sources. In this method, agents communicate with their neighbors to locate and isolate the faulty zone. Multiagent system has a decision-making ability. The DG penetration level is set to around $50 \%$. The multiagent models are simulated in MATLAB ${ }^{*} /$ Simulink $^{\circ}$ using user-defined functions and the power system is modeled using the Simscape Power Systems ${ }^{\text {tw }}$. Using multiagent system, faulted zone is successfully identified and isolated. The design applies to three-phase and unsymmetrical faults with a resistance of $0.001 \Omega$.

The main drawback of using a multiagent scheme is that in the case of large power systems, the scripts of communication languages are difficult to merge. Direct communication is also not practical because it is costly. If the number of 


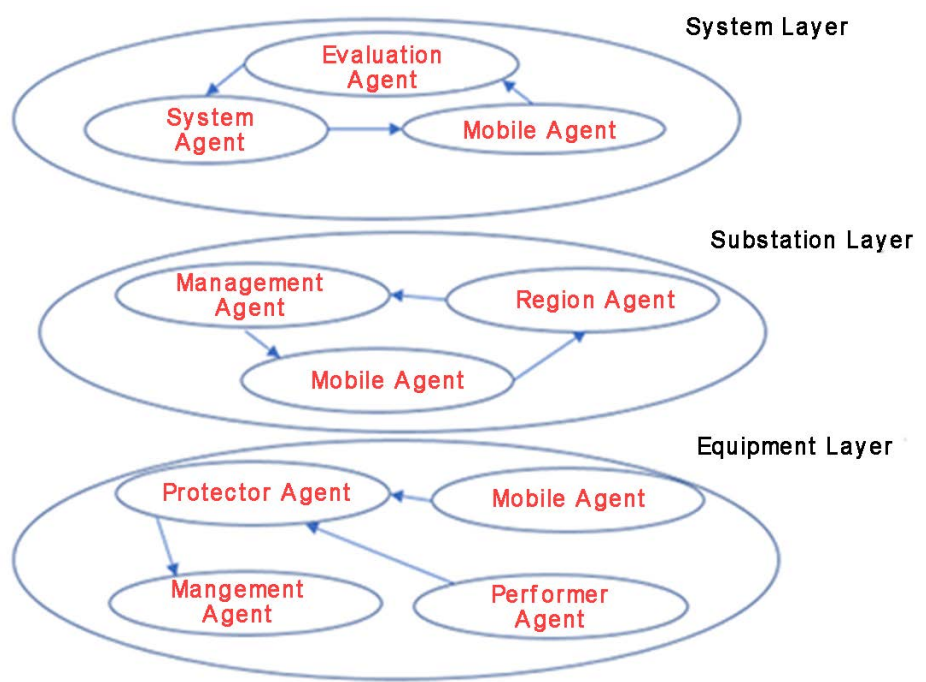

Figure 18. Architecture for multiagent protection scheme.

agents are small, this is not a big issue; but, in an environment with a huge number of programs, the expense of propagating the specifications and consequential processing of those messages is unaffordable. In this case, the only substitute is to arrange the agents in some way that prevents such broadcast. Another drawback is the difficult implementation. In direct communication schemes, each agent is accountable for communicating with other agents and must contain all the codes and data needed to support this communication. If the system could provide these competences, this would lessen the intricacy of application programs [78].

\subsection{Wide Area Protection}

This protection removes the fault much faster and more accurately based on fault information from various measurement points. This kind of protection utilizes Intelligent Electronic Devices (IEDs). These devices communicate with each other to attain the global electrical information and data from the entire power system. In this field, an adaptive fault zone matrix algorithm was suggested and enhanced by [79] [80] [81] [82]. This algorithm charts the network topology incorporating the grid connected microgrid as a region matrix by recording every state of IEDs and links the relationship to others represented by the symmetric zone (or network) matrix " $D$ " [79].

$$
\boldsymbol{D}=\left[\begin{array}{lll}
A 00 & A 01 & A 0 \cdots n \\
A 10 & A 11 & A 1 \cdots n \\
A n \cdots 0 & A n \cdots 2 & A n n
\end{array}\right]
$$

In this matrix, $A_{i i}$ denotes the total number of IEDs. Under normal conditions, it should be one, which implies the IED functions in a healthy manner; otherwise, it is zero. $A_{i j}$ equals to one means that the IED $A_{i}$ links to $A_{j}$ In other words, this indicates faulty condition. The purpose of this algorithm is to decrease the 
fault zone area after the fault current direction supervised by each relay in the matrix arrangement, which is simply carried out with the aid of a computer. It consists of three key stages: The first stage is to securely form the network matrix " $D$ " based on the structure of the network and IED " $\vec{i}$ " distribution situation. Secondly, the matrix " $D$ " should be altered to be a new fault judgment matrix Dp, utilizing the messages of the fault current direction from each IED as elaborated in [80]. Consequently, all values of $A_{i i}$ are reset to zero; and only the values of $A_{i j}$ which indicate fault current flow from IED $i$ to IED $j$ is kept " 1 ". Consequently, if the fault takes place between IED $i$ and IED $j, A_{i j}$ should be " 1 ". Hence, the fault zones can be recognized merely by a logical computation of $A_{i j}$ as articulated in the following conditions [78] [83].

$$
\begin{gathered}
\left.A_{i j}=0 \text { (Healthy Condition }\right) \\
\left.A_{i j}=1 \text { (Fault between IEDs “ } i \text { ” and “ } j ”\right)
\end{gathered}
$$

$A$ novel wide-area backup protection algorithm based on the fault component voltage distribution is suggested in [84]. The designed scheme is very useful in solving the issues of complex setting and faulty operation under power flow transfer of conventional backup protection. The measured values of voltage and current of faulty component at one terminal of the distribution line are applied to approximate the fault component voltage at the other terminal. Consequently, the fault element can be identified by computing the ratio between the measured and estimated values. Moreover, the speed of fault element identification can be augmented by a faulted area detection scheme. The suggested technique has the benefit of simple settings and flexible requirements for synchronized wide-area data. The scheme is tested on the IEEE 39-bus system. Ten synchronous generators are used as DG sources. Verification of the algorithm is performed by using PSCAD/EMTDC software environment and it considers both symmetrical and unsymmetrical faults. The flaw in the wide area protection technique is that it has only been tested for PV connected distribution grids. Moreover, it does not consider communication failures [72]. A general configuration schematic is shown in Figure 19. In the diagram, SCADA stands for Supervisory Control and Data Acquisition, LBPC stand for Local Backup Protection Centers and SBPC stands for System Backup Protection Center.

\subsection{Other Protection Schemes}

Besides the protection schemes described in previous sections, there are some other schemes which have been proposed but less frequently due to their limited scope and technical implementation difficulties. They have been grouped into three classes for simplicity. The first class of these schemes is associated with high frequency transient information. The propositions in this field are dependent on wavelet transform, using various wavelet functions applied to measurements and travelling waves involving high frequencies [48] [85]. The second class incorporates artificial-intelligence-based methods. Within this group, most of the hypotheses employ particle swarm optimization (PSO), majorly for 


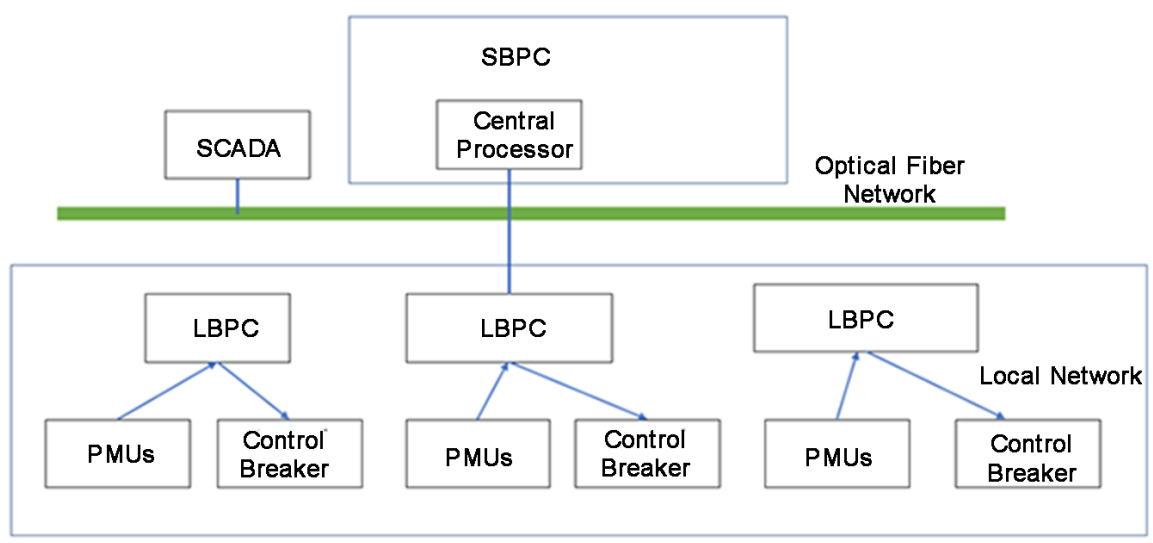

Figure 19. General configuration of wide area protection.

coordination enhancement [86]. Some researchers endorse the employment of artificial neural networks (ANN); but without carrying out any background research [87]. Some authors also mention research work using Data mining techniques conducted at Simon Fraser University (British Columbia, Canada) [88]. The third class includes proposals which rely on a purely mathematical method. Within this field, there is an extensive variety of methods ,such as using Dijkstra's Algorithm (a graph search algorithm) to attain the relay hierarchy of the power distribution system [89], a discrete idea known as "Brittleness Entropy" of a complicated network to sense faults [90], a state observer procedure as a fault detector by grouping the microgrid into various protection areas [91], using the transient fault data (polarity-time characteristics) incorporated in the preliminary current travelling waves, and applying an altered mathematical morphology analysis technology [92], and using time-colored Petri nets (place/ transition nets) for fault analysis in microgrids [93].

\section{Phasor Measurement Units (PMUs)}

A generic schematic implementation of a PMU is shown in Figure 20 [38]. The receiver section receives the Global Positioning System (GPS) transmission which then delivers a phase-locked sampling clock pulse to the analog to digital converter mechanism. The sampled data is transformed to a complex number which characterizes the sampled waveform phasor. Phasors of the three phases are merged to give the positive sequence measurement. Computation of the discrete Fourier transform (DFT) enables the signal (voltage or current) to be measured.

PMUs are effective in measuring various electrical quantities (voltages, currents, phase-angles etc.) in real-time, and can also be applied to protection of DG-connected networks. Reference [94] used DigSILENT Power Factory software to measure rotor angle of a synchronous generator with respect to the reference bus (bus 40) and reference machine (generator 39) and compared it with the theoretical value. The simulations were carried out using an IEEE-39 bus test system. The value measured by the software is treated as measured by PMU. The 


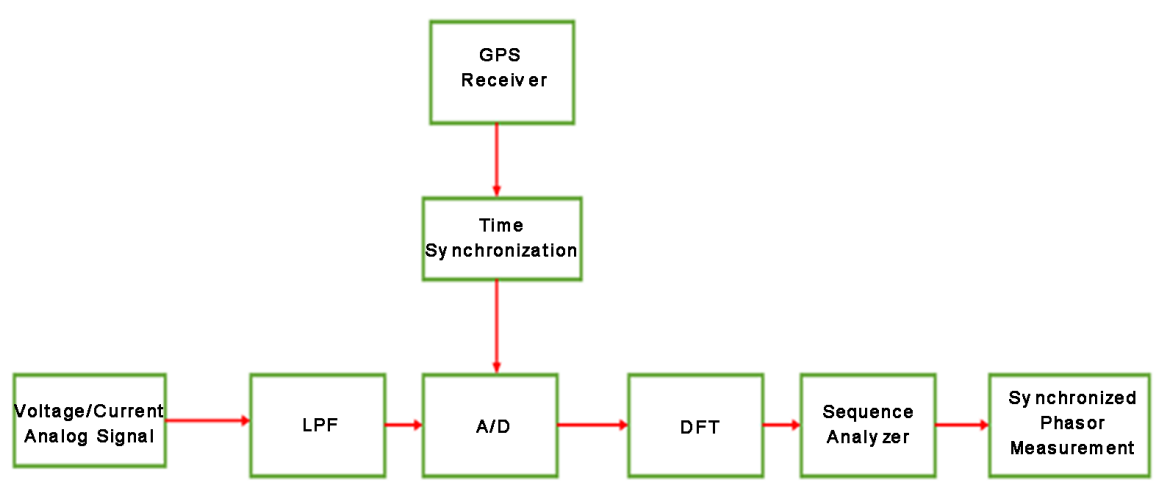

Figure 20. Phasor measurement unit block diagram implementation.

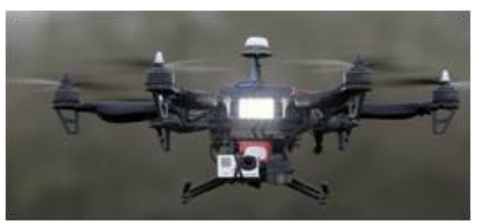

Figure 21. Drone technology.

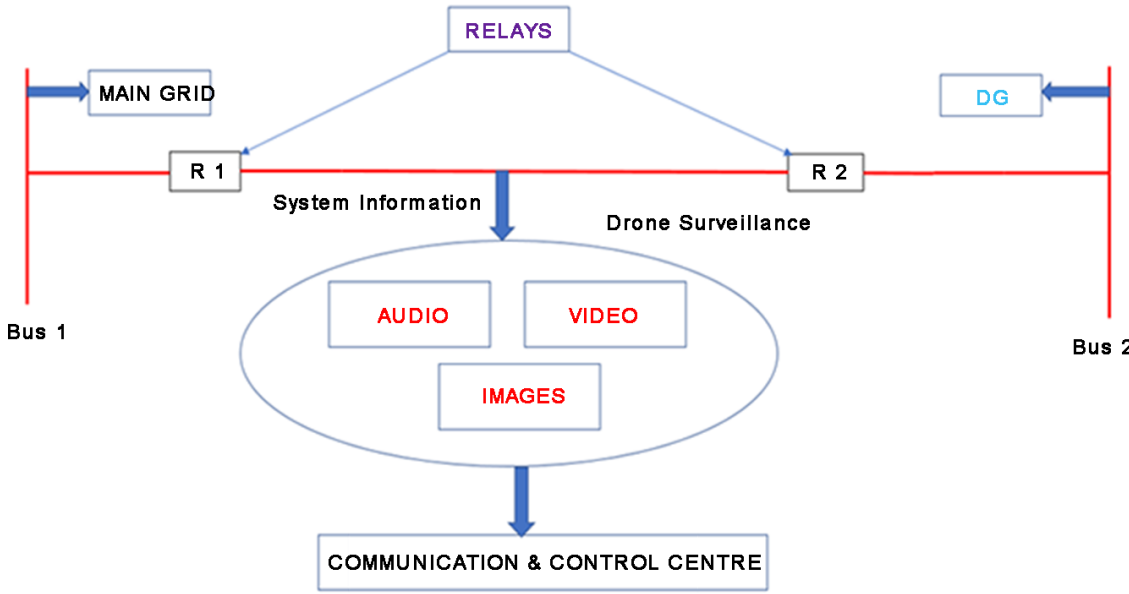

Figure 22. Suggested protection scheme using drone technology.

results are valid for three-phase bolted faults. PMUs also have their dark sides. The key hurdle in implementing PMU on a large-scale active distribution network is that the communication network needed to support this technology is quite expensive. Moreover, it is hard to monitor huge amount of output data. Communication delays should be considered which can lead to delayed action in protection signals. Algorithms are computationally heavy and distortion and harmonics can further deter the results. The use of PMUs may, in some cases, be beneficial for long transmission lines; but they have limited capabilities as far as distribution systems are concerned. Lower distances in distribution grids indicate lower amplitude and phase differences between the electric quantities at different nodes. This means more accuracy is required to correctly measure these differences. The high amount of distortion that is usually prevalent in dis- 
tribution grids may lead to a need for redefining compliance limits with harmonic intrusions which is beyond the present standard. Lastly, the nonexistence of human supervision requires a high amount of trustworthiness of the information coming from PMUs to utilize them in protection applications [95].

\section{Conclusions and Future Work}

Protection of distribution networks in the presence of DG presents many challenges. Conventional over current protection works correctly only for radial systems. Protection coordination is affected due to bidirectional power flows in DG-connected distribution systems. The aim of the current study was to comprehensively review the existing protection schemes related to DG connected distribution systems and to categorize them into specific groups. Several schemes ranging from differential and distance protection to adaptive and multiagent protection were discussed. A lot of work has been done in this direction but there is still a lot more to be explored to overcome the critical problems and improve the existing works.

As we move towards the future, there is a need to have a protection scheme which can cater to all kinds of faults and can continually provide power to consumers. The unmanned aerial vehicle (UAV), commonly known as a drone, can be employed to collect real-time data from a power network. For instance, the drone can be used to click high resolution images, record any fault system sounds and make a video of the faulted area, and then send the video back to the control and monitoring center. In other words, it can be used for surveillance and the operator can operate the desired protection scheme accordingly. This technology, although very expensive, will be beneficial as it will eventually reduce the margin of error to nearly zero and will also reduce the redundancy of having to operate more protective relays than required. A typical drone in use is shown in Figure 21. A suggested schematic for application of drone technology in protection of active distribution systems is shown in Figure 22.

Another possible future research direction could be to design and test the viability of the schemes mentioned in this paper by incorporating larger distributed generation systems with a meshed configuration instead of the conventional radial topology. Autonomous systems employing computational intelligence can also present an innovative approach to this demanding problem of protection of active distribution systems.

\section{References}

[1] Basak, P., Chowdhury, S., Halder, N.D.S. and Chowdhury, S.P. (2012) A Literature Review on Integration of Distributed Energy Resources in the Perspective of Control, Protection and Stability of Microgrid. Renewable and Sustainable Energy Reviews, 16, 5545-5556. https://doi.org/10.1016/j.rser.2012.05.043

[2] Planas, E., Gil-de-Muro, A., Andreu, J., Kortabarria, I. and Martinez de Alegria, I. (2013) General Aspects, Hierarchical Controls, and Droop Methods in Microgrids: A Review. Renewable and Sustainable Energy Reviews, 17, 147-159. https://doi.org/10.1016/j.rser.2012.09.032 
[3] Jiayi, H., Chuanwen, J. and Rong, X. (2008) A Review on Distributed Energy Resources and Micro Grid. Renewable and Sustainable Energy Reviews, 12, 2472-2483.

[4] Justo, J.J., Mwasilu, F., Lee, J. and Jung, J.W. (2013) AC-Microgrids versus DC-Microgrids with Distributed Energy Resources: A Review. Renewable and Sustainable Energy Reviews, 24, 387-405. https://doi.org/10.1016/j.rser.2013.03.067

[5] Ustun, T.S., Ozansoy, C. and Zayegh, A. (2011) Recent Developments in Microgrids and Example Cases around the World-A Review. Renewable and Sustainable Energy Reviews, 15, 4030-4041.

[6] Shahzad, U. (2015) Control Schemes for Distribution Grids with Mass Distributed Generation. International Journal of Information Technology and Electrical Engineering, 4, 14-18. http://www.iteejournal.org/archive/vol4no2/v4n2_3.pdf

[7] Shahzad, U. (2015) The Need for Renewable Energy Sources. International Journal of Information Technology and Electrical Engineering, 4, 16-19. http://www.iteejournal.org/archive/vol4no4/v4n4_4.pdf

[8] El-Khattam, W. and Salama, M.A. (2004) Distributed Generation Technologies, Definitions and Benefits. Electric Power Systems Research, 71, 119-128.

[9] Pepermans, G., Driesen, J., Haeseldonckx, D., Belmans, R. and D’haeseleer, R.W. (2005) Distributed Generation: Definition, Benefits and Issues. Energy Policy, 33, 787-798.

[10] Jiayi, H., Chuanwen, J. and Rong, X. (2008) A Review on Distributed Energy Resources and Micro Grid. Renewable and Sustainable Energy Reviews, 12, 2472-2483.

[11] Khan, S.A., Ali, R. and Hussain, S. Introduction to Microgrid. http://www.slideshare.net/Shahabkhan/microgrid-presentation

[12] Khare, A. Microgrid and Its Control. https://www.slideshare.net/anulakhare/microgrid

[13] Olivares, D.E (2014) Trends in Microgrid Control. IEEE Transactions on Smart Grids, 5, 1905-1919. https://doi.org/10.1109/TSG.2013.2295514

[14] Nthontho, M.P., Chowdhury, S.P., Winberg, S. and Chowdhury, S. (2012) Protection of Domestic Solar Photovoltaic Based Microgrid. Proceedings of the 11 th International Conference on Developments in Power Systems Protection, Birmingham, 23-26 April 2012, 1-6.

[15] Whitlock, R. (2015) Seven Benefits of Microgrids. http://interestingengineering.com/7-benefits-of-microgrids/

[16] Blackburn, J.L. (2006) Protective Relaying Principles and Applications. CRC Press, Boca Raton.

[17] Margossian, H., Deconick, G. and Sachau, J. (2015) Distribution Network Protection considering Grid Code Requirements for Distributed Generation. IET Generation, Transmission, and Distribution Journal, 9, 1377-1381. http://dx.doi.org/10.1049/iet-gtd.2014.0987

[18] Kish, G.J. and Lehn, P.W. (2012) Microgrid Design Considerations for Next Generation Grid Codes. IEEE Power Engineering Society General Meeting, San Diego, 22-26 July 2012, 1-8. https://doi.org/10.1109/PESGM.2012.6343938

[19] Preda, T., Uhlen, K. and Nordgard, D (2012) An Overview of the Present Grid Codes for Integration of Distributed Generation. CIRED Workshop on Integration of Renewables into the Distribution Grid, Lisbon, 29-30 May 2012, 1-4. https://doi.org/10.1049/cp.2012.0716

[20] Walling, R., Ellis, A. and Gonzalez, S. (2014) Implementation of Voltage and Fre- 
quency Ride-Through Requirements in Distributed Energy Resources Interconnection Standards. Technical Report (Sandia National Laboratories), Albuquerque, April 2014, 1-14.

[21] IEEE Draft Standard for Interconnection and Interoperability of Distributed Energy Resources with Associated Electric Power Systems Interface, May 2017. http://ieeexplore.ieee.org/servlet/opac?punumber=7948701

[22] Lammert, G., et al. (2014) Dynamic Grid Support in Low Voltage Grids-Fault Ride-Through and Reactive Power/Voltage Support during Grid Disturbances. Power Systems Computation Conference, Wroclaw, 18-22 August 2014, 1-7. https://doi.org/10.1109/PSCC.2014.7038468

[23] Omaha Public Power District DG Manual, a Guide to the Interconnection of DG with the OPPD System.

http://www.oppd.com/residential/residential-rates/customer-generation/

[24] LES Requirements for Interconnection of Cogeneration and Small Power Production.

http://www.les.com/pdf/net-metering-gen/requirements-interconnection-cogen.pdf

[25] NPPD Generator Connection Application.

http://www.nppd.com/about-us/power-plants-facilities/renewable-energy/distribute d-or-local-generation-connection-application/

[26] Sortomme, E., Venkata, S.S. and Mitra, J. (2009) Microgrid Protection Using Communication Assisted Digital Relays. IEEE Transactions on Power Delivery, 25, 2789-2796. https://doi.org/10.1109/TPWRD.2009.2035810

[27] Li, B., Li, Y., Bo, Z. and Klimek, A. (2009) Design of Protection and Control Scheme for Microgrid Systems. Proceedings of the 44th International Universities Power Engineering Conference (UPEC), Glasgow, 1-4 September 2009, 1-5.

[28] Hamlyn, A., et al. (2008) Adaptive Protection and Control Strategy for Interfacing Wind Generator to Distribution Grids. Proceedings IEEE Power and Energy Society, Wuhan, 17-20 October 2008, 2478-2483.

[29] Zamani, A. and Sidhu, T. (2010) A Strategy for Protection Coordination in Radial Distribution Networks with Distributed Generators. Proceedings of IEEE Power and Energy Society, Providence, 25-29 July 2010, 1-8.

[30] Favuza, S., Ippolito, M.G. and Massaro, F. (2013) Investigation of Protection Devices Coordination Effects on Distributed Generators Capacity in Radial Distribution Systems. International Conference on Clean Electric Power (ICCEP), Alghero, 11-13 June 2013, 686-692.

[31] Schweitzer, E.O., Finney, D. and Mynam, M.V (2012) Communications-Assisted Schemes for Distributed Generation Protection. IEEE PES Transmission and Distribution Conference and Exposition, Orlando, 7-10 May 2012, 1-8. https://doi.org/10.1109/TDC.2012.6281512

[32] Sortomme, E., Mapes, G.J., Foster, B.A. and Venkata, S.S. (2008) Fault Analysis and Protection of a Microgrid. 40th North American Power Symposium, Calgary, 28-30 September 2008, 1-6. https://doi.org/10.1109/NAPS.2008.5307360

[33] Javadian, S.A.M. and Llaghifam, M.R. (2008) Designing a New Protection System for Distribution Networks including DG. IET 9th International Conference on Developments in Power System Protection, Glasgow, 17-20 March 2008, 675-680. https://doi.org/10.1049/cp:20080120

[34] Al-Nasseri, H., Redfern, M.A. and Gorman, O.R. (2005) Protecting Microgrid Systems Containing Solid-State Converter Generation. Proceedings of the International 
Conference on Future Power Systems, Amsterdam, 18 November 2005, 1-5.

[35] Al-Nasseri, H., Redfern, M.A. and Li, F. (2006) A Voltage Based Protection for Microgrids Containing Power Electronic Converters. Proceedings of the IEEE Power and Energy Society General Meeting, Montreal, 18-22 June 2006, 1-7.

[36] Gopalan, S.A., Sreeram, V. and Herbert, H.C.I. (2014) A Review of Coordination Strategies and Protection Schemes for Microgrids. Renewable and Sustainable Energy Reviews, 32, 222-228.

[37] Loix, T., Wijnhoven, T. and Deconinck, G. (2009) Protection of Microgrids with a High Penetration of Inverter-Coupled Energy Sources. Proceedings of the Joint Symposium on Integration of Wide-Scale Renewable Resources into the Power Delivery System (CIGRE/IEEE-PES), Calgary, 29-31 July 2009, 1-6.

[38] Mirsaeidi, S., Mat, D., Wazir, M., Ghaffari, K. and Habibuddin, M. (2014) Progress and Problems in Microgrid Protection Schemes. Renewable \& Sustainable Energy Reviews, 37, 834-839.

[39] Nunes, J.U.N. and Bretas, A.S (2010) Impedance-Based Fault Location Formulation for Unbalanced Distribution Feeders with Distributed Generation. International Conference on Power System Technology, Hangzhou, 24-28 October 2010, 1-7.

[40] Penkov, D., Raison, B., Andrieu, C and Enacheanu, B. (2005) DG Impact on Three-Phase Fault Location. DG Uses for Fault Location Purposes. International Conference on Future Power Systems, Amsterdam, 18 November 2005, 1-6.

[41] Nunes, J.U.N and Bretas, A.S. (2011) An Impedance-Based Fault Location Technique for Unbalanced Distributed Generation Systems. Power Tech, Trondheim, 19-23 June 2011, 1-7.

[42] Brahma, S.M. (2011) Fault Location in Power Distribution System with Penetration of Distributed Generation. IEEE Transactions on Power Delivery, 26, 1545-1553. https://doi.org/10.1109/TPWRD.2011.2106146

[43] Orozco, C. and Perez-Londono, S. (2012) A Robust Method for Single Phase Fault Location considering Distributed Generation and Current Compensation. Transmission and Distribution: Latin America Conference and Exposition, Montevideo, 3-5 September 2012, 1-7.

[44] Orozco, C. and Perez-Londono, S. (2012) Single Phase to Ground Fault Locator for Distribution Systems with Distributed Generation. Transmission and Distribution: Latin America Conference and Exposition, Montevideo, 3-5 September 2012, 7-12.

[45] Aboshady, F. Alaam, M.A. and Azmy, A.M. (2013) Impedance-Based Fault Location Technique for Distribution Systems in Presence of Distributed Generation. IEEE International Conference on Smart Energy Grid Engineering, Oshawa, 28-30 August 2013, 1-6.

[46] Majumder, R., Dewadasa, M., Ghosh, A. and Ledwich, G. (2011) Control and Protection of a Microgrid Connected to Utility through Back-To-Back Converters. Electric Power Systems Research, 81, 1424-1435.

[47] Xu, M., Zou, G., Xu, C., Sun, W. and Mu, S. (2016) Positive Sequence Differential Impedance Protection for Distribution Network with IBDGs. IEEE International Conference on Power System Technology, Wollongong, 28 September-1 October 2016, 1-5. https://doi.org/10.1109/POWERCON.2016.7753871

[48] Shi, S., Jiang, B., Dong, X. and Bo, Z. (2010) Protection of Microgrid. 10th IET International Conference on Developments in Power System Protection, Manchester, 29 March-1 April 2010, 1-4.

[49] Laaksonen, H.J. (2010) Protection Principles for Future Microgrids. IEEE Transac- 
tions on Power Electronics, 25, 2910-2918.

https://doi.org/10.1109/TPEL.2010.2066990

[50] Ustun, T.S., Ozansoy, C. and Zayegh, A. (2012) Modeling of a Centralized Microgrid Protection System and Distributed Energy Resources According to IEC 61850-70420. IEEE Transactions on Power Systems, 27, 1560-1567. https://doi.org/10.1109/TPWRS.2012.2185072

[51] Mahat, P., Chen Z., Jensen, B. and Bak, C.L. (2011) A Simple Adaptive Overcurrent Protection of Distribution Systems with Distributed Generation. IEEE Transactions on Smart Grid, 2, 428-438. https://doi.org/10.1109/TSG.2011.2149550

[52] Sitharthan, R., Geethanjali, M., Karpaga, T. and Pandy, S. (2016) Adaptive Protection Scheme for Smart Microgrid with Electronically Coupled Distributed Generations. Alexandria Engineering Journal, 55, 2539-2550.

https://doi.org/10.1016/j.aej.2016.06.025

[53] Oudalav, A., et al. (2009) Novel Protection Systems for Microgrids. Advanced Architecture and Control Concepts for More Microgrids. Technical Report available at http://www.microgrids.eu/documents/688.pdf

[54] Sortomme, E., Ren, J. and Venkata, S.S. (2013) A Differential Zone Protection Scheme for Microgrids. PES General Meeting, Vancouver, 21-25 July 2013, 1-5. https://doi.org/10.1109/PESMG.2013.6672113

[55] Conti, S., Raffa, L. and Vagliasindi, U. (2009) Innovative Solutions for Protection Schemes in Autonomous MV Microgrids. International Conference on Clean Electrical Power, Capri, 9-11 June 2009, 647-654.

[56] Ranjbar, S. and Jamali, S. (2014) Comprehensive Protection of Medium-VoltageMicrogrids. Smart Grid Conference, Tehran, 9-10 December 2014, 1-7. https://doi.org/10.1109/SGC.2014.7150707

[57] Samantaray, S.R., Joos, G. and Kamwa, I. (2012) Differential Energy Based Microgrid Protection against Fault Conditions. IEEE PES Innovative Smart Grid Technologies (ISGT), Washington, 16-20 January 2012, 1-7.

[58] Kar, S. and Samantaray, S.R. (2014) Time-Frequency Transform-Based Differential Scheme for Microgrid Protection. IET Generations, Transmission \& Distribution, 8, 310-320. https://doi.org/10.1049/iet-gtd.2013.0180

[59] Kauhaneimi, K. and Memon, A.A. (2015) A Critical Review of AC Microgrid Protection Issues and Available Solutions. Electric Power Systems Research, 129, 23-31.

[60] Hosseini, S.A., Abyaneh, H.A., Sadeghi, S.H.H., Razavi, F. and Naseri, A. (2016) An Overview of Microgrid Protection Methods and the Factors Involved. Renewable and Sustainable Energy Reviews, 64, 174-186.

[61] Ates, Y., Uzunoglu, M., Karakas, A. and Boynuegri, A.R. (2014) The Case Study Based Protection Analysis for Smart Distribution Grids including Distributed Generation Units. $12^{\text {th }}$ IET International Conference on Developments in Power System Protection, Copenhagen, 31 March-3 April 2014, 1-5.

[62] Rezaei, N., Othman, M.L., Izzri, N., Wahab, A. and Hizam, H. (2014) Coordination of Overcurrent Relays Protection Systems for Wind Power Plants. International Conference on Power and Energy, Kuching, 1-3 December 2014, 394-399. https://doi.org/10.1109/PECON.2014.7062477

[63] Haron, A.R., Mohamed, A. and Shareef, H. (2013) Coordination of Overcurrent, Directional and Differential Relays for the Protection of Microgrid System. Procedia Technol., 11, 366-373. https://doi.org/10.1016/j.protcy.2013.12.204

[64] Jain, D.K., Gupta, P. and Singh M. (2015) Overcurrent Protection of Distribution 
Network with Distributed Generation. IEEE Innovative Smart Grid Technologies-Asia (ISGT ASIA), Bangkok, 3-6 November 2015, 1-6. https://doi.org/10.1109/ISGT-Asia.2015.7387143

[65] Kennedy, J., Ciufo, P. and Agalgaonkar, A. (2016) A Review of Protection Systems for Distribution Networks Embedded with Renewable Generation. Renewable and Sustainable Energy Reviews, 58, 1308-1317. https://doi.org/10.1016/j.rser.2015.12.258

[66] Vijeta, K. and Sarma, D. (2012) Protection of Distributed Generation Connected Distribution System. International Conference on Advances in Power Conversion and Energy Technologies, Mylavaram, 2-4 August 2012, 1-6. https://doi.org/10.1109/APCET.2012.6302064

[67] Sherbilla, N.F., Kawady, T.A., Elkalashy, N.I. and Taalab, A.I. (2011) Modified Setting of Overcurrent Protection for Distribution Feeders with Distributed Generation. IET Conference on Renewable Power Generation, Edinburgh, 6-8 September 2011, 1-6. https://doi.org/10.1049/cp.2011.0168

[68] Brearley, B.J. and Prabu, R.R. (2017) A Review on Issues and Approaches for Microgrid Protection. Renewable and Sustainable Energy Reviews, 67, 988-997. https://doi.org/10.1016/j.rser.2016.09.047

[69] Dewadasa, M.J. (2008) Distance Protection Solution for a Converter Controlled Microgrid. Proceedings of the 15th National Power Systems Conference, Mumbai, 1-2 December 2008, 586-591.

[70] Lin, H., Liu, C., Guerrero, J.M. and Vasquez, J.C. (2015) Distance Protection for Microgrids in Distribution System. IECON 41 st Annual Conference of the IEEE Industrial Electronics Society, Yokohama, 9-12 November 2015, 731-736. https://doi.org/10.1109/IECON.2015.7392186

[71] Chilvers, I., Jenkins, N. and Crossley, P. (2005) Distance Relaying of $11 \mathrm{kV}$ circuits to Increase the Installed Capacity of Distributed Generation. IEE Proceedings-Generation, Transmission and Distribution, 152, 40-46. https://doi.org/10.1049/ip-gtd:20041205

[72] Chaun, L. (2014) An Update on Power Quality. Intech-Open, Sydney.

[73] Colson, C.M. and Nehrir, M.H. (2009) A Review of Challenges to Real-Time Power Management of Microgrids. Power \& Energy Society General Meeting, Calgary, 26-30 July 2009, 1-8. https://doi.org/10.1109/PES.2009.5275343

[74] Coury, D.V., Throp, J.S., Hopkinson, K.M. and Birman, K.P. (2000) Agent Technology Applied to Adaptive Relay Setting for Multi-Terminal Lines. IEEE Power \& Energy Society Summer Meeting, Seattle, 16-20 July 2000, 1-6.

[75] Lakruwan, K.A. (2012) Multi Agent Based Control and Protection for an Inverter Based Microgrid. Master's Thesis, University of Moratuwa, Moratuwa, Srilanka.

[76] Tian, F., Wen, F., Wang, X., Xue, Y. and Salam, M.A. (2016) A Multi-Agent System Based Fault Diagnosis for Active Distribution Systems. IEEE Innovative Smart Grid Technologies-Asia (ISGT-Asia), Melbourne, 28 November-1 December 2016, 1-4. https://doi.org/10.1109/ISGT-Asia.2016.7796541

[77] Hussein, O.A. and Rao, P.V.R. (2016) Fault Location and Isolation Using Multi Agent Systems in 16 Buses Distribution System. International Journal of Electrical and Electronics Engineering Research, 6, 21-38.

[78] Glavic, M. (2006) Agents and Multi-Agent Systems: A Short Introduction for Power Engineers. http://www.montefiore.ulg.ac.be/ glavic/MAS-Intro_Tech_report.pdf

[79] Chao, Y. (2009) Novel Protection Methods of Distributed Generation System. Changsha University of Science \& Technology, Changsha. 
[80] Xia, L., Yuping, L. and Lianhe, W. (2008) New Fault Region Location Scheme in Distribution System with DGs. Transactions of China Electrotechnical Society, 23, 139-145.

[81] Xia, L., Yuping, L. and Lianhe, W. (2008) New Current Protection Scheme Considering Distributed Generation Impact. Automation of Electric Power Systems, 32, 50-56.

[82] Ning, W., Yang, X. and Yuping, L. (2009) New Fault Section Location Algorithm for Distribution Network with DG. Automation of Electric Power Systems, 33, 77-82.

[83] Miveh, M.R., Gandomkar, M., Mirsaeidi, S. and Gharibdoost, M.R. (2012) A Review on Protection Challenges in Microgrids. 17 th Conference on Electrical Power Distribution Networks, Tehran, 2-3 May 2012, 1-5.

[84] He, Z., et al. (2011) Wide-Area Backup Protection Algorithm Based on Fault Component Voltage Distribution. IEEE Transactions on Power Delivery, 26, 2752-2760. https://doi.org/10.1109/TPWRD.2011.2165971

[85] Han, Y., Xuehao, H. and Dongxia, Z. (2010) Study on Applying Wavelet Transform to the Protection Algorithm of Microgrid Dominated by Inverter-Interfaced DGs. $10^{\text {th }}$ International Conference on Power System Technology (POWERCON), Hangzhou, 24-28 October 2010, 1-6. https://doi.org/10.1109/POWERCON.2010.5666119

[86] Zeineldin, H.H., Salama, M.M.A. and El-Saadany, E.F. (2006) Optimal Coordination of Overcurrent Relays Using a Modified Particle Swarm Optimization. Electric Power Systems Research, 76, 988-995.

[87] Balantrapu, S. Role of Artificial Neural Networks in Microgrid. http://www.energycentral.com/c/iu/role-artificial-neural-networks-microgrid

[88] Joós, G., et al. (2007) Modeling Protection for DGs and Microgrids Using Data Mining. Nagoya Microgrid Symposium, Nagoya, 6th April 2007.

[89] Ustun, T.S., Ozancoy, C. and Zayegh, A. (2011) Implementation of Dijkstra's Algorithmin a Dynamic Microgrid for Relay Hierarchy Detection. IEEE International Conference on Smart Grid Communications, Brussels, 17-20 October 2011, 481-486.

[90] Guang, H., Rong, P., Wei, Q. and Jia, D. (2011) Brittleness Entropy of Complex System Based Protection of Microgrid. 6th International Forum on Strategic Technology, Harbin, 22-24 August 2011, 433-436.

[91] Esreraig, M. and Mitra, J. (2011) An Observer-Based Protection System for Microgrids. Power and Energy Society General Meeting, Detroit, 24-29 July 2011, 1-7.

[92] Li, X., Dysko, A. and Burtg, G. (2012) Enhanced Protection for Inverter Dominated Microgrid Using Transient Fault Information. 11th International Conference on Developments in Power Systems Protection, Birmingham, 23-26 April 2012, 1-5. https://doi.org/10.1049/cp.2012.0081

[93] Shi, J., Sun, W.S. and Li, C.L. (2012) Fault Diagnosis of Microgrid Based on Advanced Petri Net. Applied Mechanics and Materials Periodical, 130-134, 3015-3018. https://doi.org/10.4028/www.scientific.net/AMM.130-134.3015

[94] Heidary, M., Alikhanlou, S. and Aghamohammadi, M.R. (2014) Estimation of Rotor Angle Based on Operating Variables Measured by PMU. Proceedings of IAJC International Conference, Orlando, 25-27 September 2014, 1-10.

[95] Das, S. Challenges of Phasor Measurement Unit. http://www.slideshare.net/sarasijdas/challenges-of-phasor-measurement-units 
Submit or recommend next manuscript to SCIRP and we will provide best service for you:

Accepting pre-submission inquiries through Email, Facebook, LinkedIn, Twitter, etc. A wide selection of journals (inclusive of 9 subjects, more than 200 journals)

Providing 24-hour high-quality service

User-friendly online submission system

Fair and swift peer-review system

Efficient typesetting and proofreading procedure

Display of the result of downloads and visits, as well as the number of cited articles Maximum dissemination of your research work

Submit your manuscript at: http://papersubmission.scirp.org/

Or contact epe@scirp.org 